\title{
In Vitro Models for Studying Secondary Plant Metabolite Digestion and Bioaccessibility
}

\author{
M. Alminger, A.-M. Aura, T. Bohn, C. Dufour, S.N. El, A. Gomes, S. Karakaya, M.C. Martínez-Cuesta, G.J. McDougall, T. Requena, \\ and C.N. Santos
}

\begin{abstract}
There is an increased interest in secondary plant metabolites, such as polyphenols and carotenoids, due to their proposed health benefits. Much attention has focused on their bioavailability, a prerequisite for further physiological functions. As human studies are time consuming, costly, and restricted by ethical concerns, in vitro models for investigating the effects of digestion on these compounds have been developed and employed to predict their release from the food matrix, bioaccessibility, and assess changes in their profiles prior to absorption. Most typically, models simulate digestion in the oral cavity, the stomach, the small intestine, and, occasionally, the large intestine. A plethora of models have been reported, the choice mostly driven by the type of phytochemical studied, whether the purpose is screening or studying under close physiological conditions, and the availability of the model systems. Unfortunately, the diversity of model conditions has hampered the ability to compare results across different studies. For example, there is substantial variability in the time of digestion, concentrations of salts, enzymes, and bile acids used, $\mathrm{pH}$, the inclusion of various digestion stages; and whether chosen conditions are static (with fixed concentrations of enzymes, bile salts, digesta, and so on) or dynamic (varying concentrations of these constituents). This review presents an overview of models that have been employed to study the digestion of both lipophilic and hydrophilic phytochemicals, comparing digestive conditions in vitro and in vivo and, finally, suggests a set of parameters for static models that resemble physiological conditions.
\end{abstract}

Keywords: phytochemicals, carotenoids, polyphenols, gastrointestinal digestion, in vitro models, bioacessibility

\section{Introduction}

Phytochemicals are a large and structurally diverse group of secondary plant metabolites that are nonessential for humans, that is, their nonconsumption does not cause any specific deficiency symptoms. For the plant, these are also nonessential compounds, but they aid, among other functions, in fending off herbivores (polyphenols), or stabilizing photosynthetic pigments (carotenoids). From a chemical point of view, phytochemicals in-

MS 20131681 Submitted 15/11/2013, Accepted 28/2/2014. Author Alminger is with Dept. of Chemical and Biological Engineering, Chalmers Univ. of Technology, SE 412 96, Gothenburg, Sweden. Author Aura is with VTT Technical Research Centre of Finland, P.O.Box 1000, Tietotie 2, Espoo, FI-02044 VTT, Finland. Autho Bohn is with Environment and Agro-biotechnologies Dept, Centre de Recherche Public - Gabriel Lippmann, 4422 Belvaux, Luxembourg. Author Dufour is with INRA UMR 408 Safety and Quality of Plant Products F-84000 Avignon, France. Author Dufour is also with Univ. of Avignon, UMR 408 Safety and Quality of Plant Products F-84000 Avignon, France. Authors El and Karakaya are with Engineering Faculty Dept. of Food Engineering, Ege Univ. 35100 Izmir, Turkey. Authors Gomes and Santos are with Inst. de Biologia Experimental e Tecnológica, Apartado 12, 2781-901 Oeiras, Portugal. Authors Gomes and Santos are also with Inst. de Tecnologia Química e Biológica, Univ. Nova de Lisboa, Av. da República, EAN, 2781-901 Oeiras, Portugal. Authors Martínez-Cuesta and Requena are with Inst. de Investigación en Ciencias de la Alimentación CIAL (CSIC-UAM), Nicolás Cabrera 9, 28049 Madrid, Spain. Author McDougall is with The James Hutton Inst., Invergowrie, DD2 5DA, Dundee, United Kingdom. Direct inquiries to author Santos (E-mail csantos@itqb.unl.pt). clude very diverse compounds, from the rather polar polyphenols, to the rather apolar carotenoids, phytosterols, and terpenes.

There has been increased interest in phytochemicals as their consumption and body tissue levels have been associated with several health benefits, especially in relation to the prevention of chronic diseases such as diabetes, cancer, cardiovascular diseases (CVD) and neurodegenerative diseases (Krzyzanowska and others 2010). This is especially true for their consumption of whole fruits and vegetables, even though there is controversy about the compounds and mechanisms responsible for the observed health benefits. Nevertheless, a number of prospective studies have related the consumption of phytochemicals, such as of polyphenols and carotenoids, in form of whole fruits or vegetables with the prevention of chronic diseases (He and others 2007; Carter and others 2010). For example, in various meta-analyses, the consumption of carotenoids and several types of polyphenols such as flavonoids were inversely related to the incidence of CVD (Arts and Hollman 2005; Hamer and Chida 2007).

The possible effectiveness, in the human body, of phytochemicals is greatly determined by the bioavailability of these bioactive molecules. The most abundant phytochemicals in our diet are not necessarily those able to result in the highest tissue concentrations or those revealing biological effects, owing to considerable differences in bioavailability (Manach and others 2005). Phytochemical bioavailability is affected by a large number of factors including the types of compounds studied, variation in polarity, molecular 
mass, their differing associations with the plant matrix, presence in crystalline or amorphous state, digestion by gastrointestinal (GI) enzymes, active compared with passive absorption into the enterocytes, and many more. Among the most important factors determining bioavailability, and a prerequisite for intestinal absorption, is release from the food matrix and solubilization during digestion, also termed bioaccessibility (Parada and Aguilera 2007). Bioacessibility is, therefore, describing the fraction of a compound potentially available for further uptake and absorption. The amount of any phytochemical bioacessible may differ greatly from its total concentration in the native food matrix. For some compounds that are poorly released and solubilized, such as carotenoids (Bohn 2008), or that are degraded prior to reaching their site of absorption, such as anthocyanins, the portion that is bioaccessible may be below 10\% (Minekus and others 1995; Bouayed and others 2011). Thus, a thorough understanding of changes occurring during digestion (such as mechanical action, enzymatic activities, and altered $\mathrm{pH}$ ) is crucial for the understanding of bioaccessibility and estimating bioavailability and bioactivity, as only bioavailable phytochemicals will exert fully their potential beneficial effects. Because animal and human studies are lengthy and costly to conduct, and are limited due to ethical considerations, in vitro systems have been developed that enable the prediction of phytochemical changes during oral and GI digestion. This has allowed the screening of comparatively large numbers of samples and/or conditions, studying the separate and combined impacts of each stage of digestion on the release and availability of phytochemicals, which would hardly be possible in vivo.

A major obstacle for the interpretation of phytochemical bioaccessibility based on in vitro studies is the large number of published models since the description of the 1st model developed for studying iron bioaccessibility (Miller and others 1981). The diversity of models has hampered the comparison of results across studies, and increased the chances of finding contradictory results. The employed models mainly differ in the inclusion of various stages of digestion (oral, gastric, small intestinal, large intestinal); digestion times; $\mathrm{pH}$; the nature of digestive enzymes involved; and concentrations of electrolytes and bile acids. Finally, while most of the models are operated in static mode (that is, with prefixed concentrations and volumes of digested materials, enzymes salts, and so on), there are also a limited number of dynamic models that mimic the continuous changes of the physicochemical conditions, and aim to better simulate the passage of the bolus/digesta through the human digestive tract. However, these models are much more labor- and cost-intensive than the static models.

The aim of this review is to summarize frequently employed models for studying phytochemical bioaccessibility, to compare conditions to the situation in vivo, and to suggest a set of variables and values that appear closest to conditions in vivo, in order to contribute to the standardization of in vitro models. One of the major differences between the reported models, apart from being static or dynamic, is their application to either hydrophilic or lipophilic compounds (Figure 1).

For practical reasons, this review focuses on 2 major groups of phytochemicals: polyphenols as the major hydrophilic phytochemicals and carotenoids, as the major lipophilic phytochemicals; aiming to elucidate factors affecting the choices of the appropriate model for each application in order to simulate in vivo conditions to the best of present knowledge. Thus, the review is structured, 1 st, into a discussion on general aspects of digestion, and 2nd, to provide more thorough insights into the individual digestion phases themselves.

\section{Parameters That Drive the Choice of Model}

There are a number of factors that drive the choice of a model system (Figure 1). The most important is the desired outcome of the study. In some studies, the prime objective is to understand the effect of simulated GI digestion on a certain class of phytochemicals (hydrophilic or lipophilic). For a limited selection of samples, in-depth simulation of a dynamic system may be more appropriate as it allows simulation of the effects of multiple digestive parameters on a small number of samples. Larger scale studies may require screening of the effect of in vitro digestion on multiple samples (such as different source materials or the effects of processing/cooking) and a relatively simple static model may be more appropriate (Figure. 1).

In some cases, the function of in vitro digestion is to provide samples that are more physiologically relevant for further studies on potential bioactivities, as with the preparation of "colonavailable" samples for investigating effects on colon cancer models (Brown and others 2012) or the preparation of dietary fiber fractions such as $\beta$-glucans (Beer and others 1997).

Of course, there is considerable flexibility in the approaches. Initial hypotheses could be tested in the static models and then extended in dynamic model experiments. Insights gained from dynamic models could be fed back into the design of more physiologically appropriate screening methods (Figure 1).

\section{Overview on Parameters Affecting the Release and Chemical Changes of Lipophilic and Hydrophilic Phytochemicals during Digestion}

Digestion of phytochemicals is a complex process, and the bioaccessibility of phytochemicals depends on both the characteristics of the food matrix and the physiological conditions encountered in the various compartments of the GI tract (including enzyme concentrations and $\mathrm{pH}$ ). Additionally, the physicochemical properties of the phytochemicals themselves are important parameters. For example, the hydrophilicity/lipophilicity balance is crucial in driving the solubilization of hydrophilic phenolic compounds into the aqueous phase of the intestinal digesta and the restructuring of lipophilic carotenoids into mixed micelles.

Since plant foods are often diverse in composition or eaten in conjunction with other foods, food bolus constituents are likely to modulate the bioaccessibility and stability of phytochemicals. This may contribute to the rather small fraction of dietary phytochemicals that is typically absorbed and utilized by humans (Schramm and others 2003). Therefore, defining the conditions that influence their absorption can provide significant insights into methods for maximizing the utilization of these potential health-promoting constituents. The main food components are proteins, carbohydrates, fiber, and fat, and their interactions with phytochemicals are often not considered. When considering in vitro bioaccessibility studies, chemical reactions (such as oxidation/reduction or complexation), biochemical reactions (enzyme/substrate interaction), or physical constraints (diffusion) occuring within food must be taken into account. For polyphenols, in particular, these types of interactions have rarely been taken into account when determining polyphenol digestion (Ortega and others 2009).

\section{Lipophilic phytochemicals}

The absorption of lipophilic phytochemicals mainly occurs after the disruption of the food matrix, enabling the release and emulsification into lipid droplets in the stomach, followed by incorporation into mixed micelles. Although the lipophilic carotenoids 


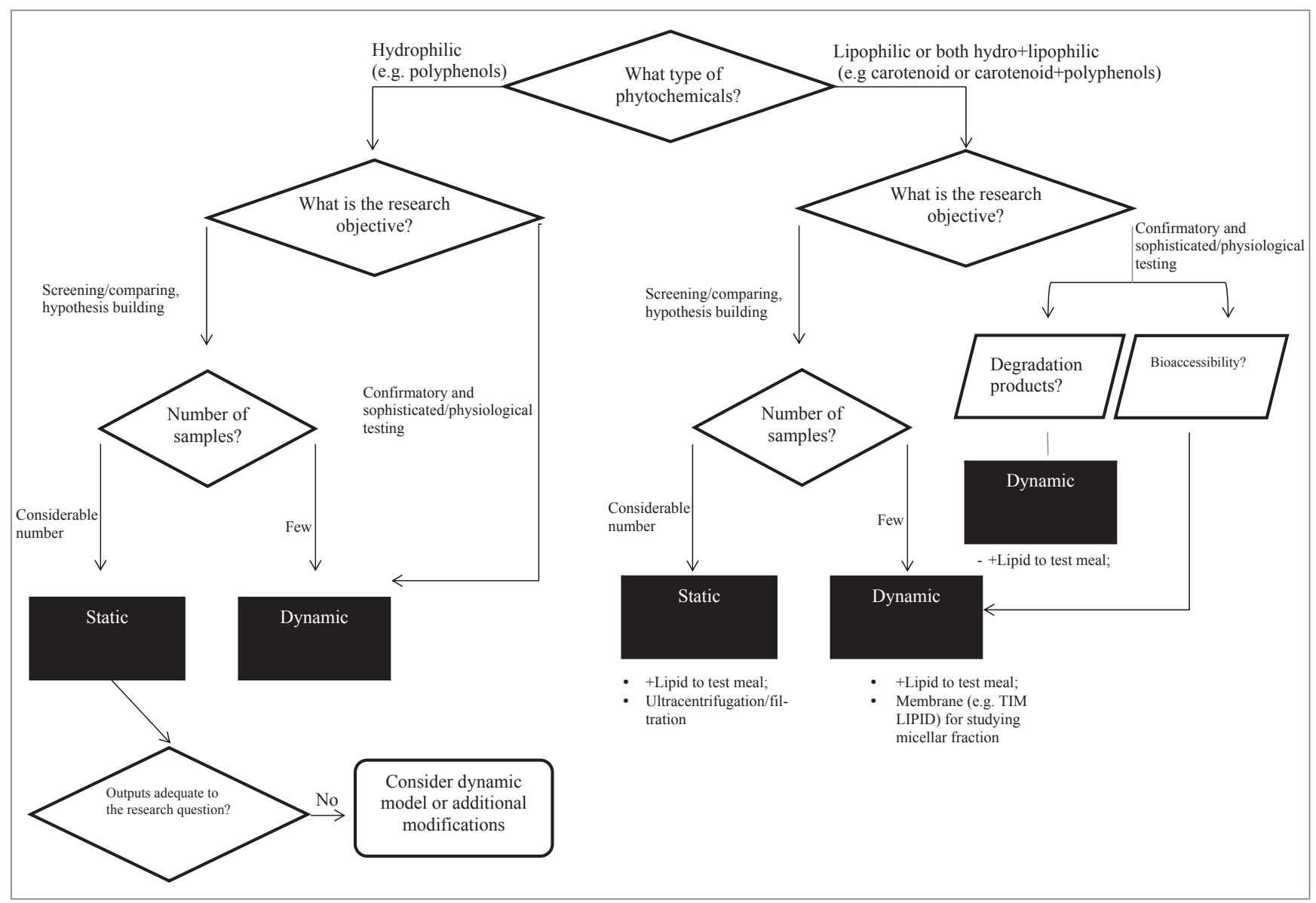

Figure 1-Decision tree for choosing an in vitro digestion model: some a priori considerations. Major aspects concern lipophilicity of the phytochemical, as well as amount sample material and number of samples.

are considered as relatively labile under acidic conditions, no significant chemical modification in the human stomach has been described (Tyssandier and others 2003). Some isomerization was observed in the stomach of ferrets (Boileau and others 1999) and relatively high recoveries of dietary carotenoids (65\% to $91 \%$ ) have been observed after GI in vitro digestion (Granado-Lorencio and others 2007; Failla and others 2009). The digestive stability of carotenoids in different food matrices has been investigated in a dynamic in vitro model (TIM 1) that simulates the stomach and small intestine (Blanquet-Diot and others 2009; Déat and others 2009). Zeaxanthin and lutein (xanthophylls) were found to be stable during the whole digestion, whereas lycopene and $\beta$-carotene (carotenes) were stable in the gastric and duodenal compartments but partly degraded in the jejunal and ileal compartments of the small intestine, perhaps due to delayed release from the matrix and later micellarization of these carotenes at this stage (Blanquet-Diot and others 2009). Although an enhanced release from the matrix can contribute to higher bioaccessibility, the released carotenoids may be more susceptible to degradation and isomerization (Failla and others 2008a). In the study by Blanquet-Diot and others (2009), a degradation of $\beta$-carotene and all-trans lycopene, not directly related with the formation of $c$ is isomers, was observed in the lowest part of the small intestine. As suggested by the authors, the results might be due to breakdown to nondetected metabolites (such as oxidation products) or enzyme-catalyzed cleavage products during small intestinal digestion, but no precise data could support this hypothesis. Apart from the food matrix, carotenoid bioavailability may be influenced by the presence of other nutrients and nonnutrients within the food. For example, a competition between carotenoids and other fat-soluble nutrients such as vita$\min \mathrm{E}$ at the absorption stage has been reported (Faulks and others 1998). Differences in location and form will also affect carotenoid release and bioavailability. Xanthophylls are often associated with proteins, for example, lutein in green leafy vegetables is located in chloroplasts, whereas carotenes are found in chloroplasts as oil droplets, such as in fruits, or semicrystalline membrane-bound solids like in carrot, tomato, and papaya (Faulks and others 1998; Schweiggert and others 2012).

Garrett and others (1999) developed a modified method of the in vitro digestion model to assess the transfer efficiency of pure carotenoids from dietary lipids into synthetic mixed micelles. Sy and others (2012a) found that lutein was more readily micellarized than the other carotenoids and especially compared with lycopene, which was the least micellarized carotenoid. The apparent poor solubility and bioaccessibility of lycopene may be related to its elongated shape which could be responsible for the molecule being extruded from the micelles into the surrounding aqueous environment, and similar effects could be expected for other lipophilic phytochemicals.

\section{Hydrophilic phytochemicals}

Phenolic phytochemicals can greatly vary in their chemical structure and properties, ranging from simple molecules (such as phenolic acids) to highly polymerized molecules 
(proanthocyanidins) (Manach and others 2004). This chemodiversity results in different bioaccessibility. Factors in the bioaccessibility of polyphenols include their release from the food matrix, particle size, their hydrophilic/lipophilic balance as related to their glycosylation, different $\mathrm{pH}$-dependent transformations (degradation, epimerization, hydrolysis, and oxidation within the GI tract), and also interactions between polyphenols and food components (Stahl and others 2002; Karakaya 2004). Phenolic compounds can have strong affinities with human salivary proline- and histidinerich proteins and form both noncovalent and covalent associations depending on the size of the phenolic compound (de Freitas and Mateus 2001; Wroblewski and others 2001). High-molecular weight polyphenols (such as tannins) can also interact strongly with fibers and proteins, but their affinity is related to their size and their solubility in water.

More hydrophobic phenolic compounds bind more strongly to proteins (Le Bourvellec and Renard 2011). Laurent and others (2007) investigated the behavior of phenolics from grape seed extract during in vitro digestion (with $\alpha$-amylase from human saliva, porcine pepsin, pancreatin, and bile extract), combined with a Caco-2 cell model to evaluate the impact of brush border proteins. Flavan-3-ol monomers $((+)$-catechin and (-)-epicatechin) and procyanidin dimers (B2 and B3) were stable during oral and gastric digestion and polyphenols interacted with proteins from both pancreatic secretions and brush border cells during the intestinal step. Simulated digestion of anthocyanins from, for example, berries, red wine, and red cabbage have shown that these compounds appear to be stable at the acidic conditions of the stomach but less stable at the small intestinal $\mathrm{pH}$ (Gil-Izquierdo and others 2002; McDougall and others 2005a, 2007). The total recovery of anthocyanins from red cabbage was low (around 25\%), possibly due to degradation into new phenolic components by the combination of the elevated $\mathrm{pH}$ and the presence of oxygen during pancreatic digestion (McDougall and others 2007). Anthocyanins may be protected from degradation in the small intestine by using encapsulation techniques, such as microcapsule systems composed of amidated pectin with or without shellac coating or whey proteins (Oidtmann and others 2012).

In summary, the digestive stability of carotenoids depends on the molecular nature and the food matrix in which they are included, with xanthophylls being more stable than carotenes. The absorption of carotenoids depends on an efficient release from the food matrix and subsequent solubilization in mixed micelles. By contrast, micellarization is generally not required for cellular uptake of phenolic compounds. However, some constituents such as anthocyanins may be rapidly degraded due to increasing $\mathrm{pH}$ (McDougall and others 2007) and the affinity of polyphenols for proteins (Dangles and Dufour 2005, 2008) may lead to a major modulation of both polyphenol absorption and reactivity in the stomach and in the upper intestine.

\section{Before Modeling: Considerations with Respect to Pre- treatments, Meal Size, and Choice of Test Meals}

According to food composition, the way it is processed and the interaction of phytochemicals with other food components (be they lipophilic or hydrophilic), the released amount of phytochemicals from the food matrix may be altered and, therefore, modify their bioaccessibility either by increasing or decreasing it.

\section{Influence of the plant matrix and food bolus}

Plant cell walls act as a barrier to digestion (Ellis and others 2004; Mandalari and others 2010). When a plant cell is broken through mastication or crushing in industrial or domestic processing, phytochemicals may associate with dietary fibers leading to a modulation of their relative bioaccessibilities. In a recent study, comparing the stability and bioaccessibility of carotenoids in pure forms (synthetic $\beta$-carotene or retinyl palmitate solution) or from food (carrot juice and raw or cooked spinach), Courraud and others (2013) demonstrated that vitamin A and carotenoid standards (synthetic $\beta$-carotene or retinyl palmitate solution) were unstable, whereas food carotenoids were generally better protected by the food matrix $30 \%$ to $100 \%$ recovery compared with $7 \%$ to $30 \%$ for standards). Although, the susceptibility of carotenoids to degradation and isomerization has been found to increase after their release from the food matrix (Failla and others 2008b), interactions with compounds released from the food matrix (including soluble fibers) and the overall viscosity may affect their bioaccessibility (McClements and others 2008; Schweiggert and others 2012). For example, the bioaccessibility of $\beta$-carotene is known to be influenced by strong binding to pectins (Ornelas-Paz and others 2008).

Dietary fibers are the main carriers for phenolic compounds and thus influence their bioaccessibility, as fiber-entrapped polyphenols are both poorly extractable and barely soluble in the GI fluids. High-molecular weight proanthocyanidins and hydrolyzable tannins represent more than $75 \%$ of all food polyphenols ingested (Arranz and others 2010) and may bind tightly to dietary fibers and this restricts their accessibility. Soluble and insoluble polysaccharides can bind phenolic compounds and limit their diffusion and substrate-enzyme contacts during GI digestion while increasing the viscosity of the medium (Eastwood and Morris 1992). During the in vitro digestion of cocoa powder, protease and glycosidase actions as well as microbiota activity were shown to influence the release of flavanols from matrix fibers and proteins (Fogliano and others 2011). Additionally, the extractability of phenolic acids, flavonoids, and proanthocyanidins appeared to be improved in the presence of fat, increasing by a 1.5 to 3 factor for cocoa liquor ( $50 \%$ fat content) compared to cocoa powder (15\% fat content) (Ortega and others 2009).

The affinity of milk and egg proteins as well as gelatins for polyphenols depends on both the protein and phenolic structures (Bohin and others 2012). For example, chlorogenic acid associates with milk caseins rather than with $\beta$-lactoglobulin, and this complexation was relatively stable in simulated gastric and intestinal steps (Dupas and others 2006). Despite these interactions, chlorogenic acid absorption by Caco-2 cells and rats was not reduced by milk addition to coffee. More than $60 \%$ of green tea flavanols (such as epicatechingallate, epigallocatechin, and epigallocatechingallate), which are very prone to oxidation, disappeared in the intestinal phase during in vitro digestion (Haratifar and Corredig 2014). A protective effect was caused by the addition of pure ascorbic acid, by citrus juices, as well as by bovine, rice, and soy milks. While ascorbic acid contribution reflects its superior antioxidant capacity compared to tea flavanols, the protection by proteins was partially reversed by increasing the content of digestive enzymes, suggesting noncovalent interactions between bovine milk proteins and galloylated tea flavanols (Green and others 2007).

Soy isoflavones appear to be more bioaccessible from fruit juices and chocolate bars compared to cookies in in vitro conditions, perhaps due to their lower diffusion rate from the carbohydrate/protein matrix of the cookies (de Pascual-Teresa and others 2006). However, a complementary human intervention study did not point out any significant difference in bioavailability parameters (area under plasma-time curve, $t_{\max }$ or $c_{\max }$ ) of these 
isoflavones. Similarly, the in vitro biacessibility of catechin was significantly higher in beverages than in confections (Neilson and others 2009). Higher amounts of isoflavones were also released in vitro from custards thickened with starch rather than with carboxymethylcellulose (Sanz and Luyten 2006). This effect was attributed to the hydrolysis of starch by $\alpha$-amylase which occurs from the mouth to the intestine. Finally, bile salts were critical to improve the in vitro bioaccessibility of isoflavone aglycones from soy bread through micellarization of these poorly soluble molecules (Walsh and others 2003).

\section{Impact of processing}

Previous studies (Garrett and others 1999) have indicated that food processing and presence of dietary fat can enhance carotenoid bioaccessibility. Cooking and heat treatment may enhance carotenoid bioaccessibility due to disruption of plant tissue and denaturation of carotenoid-protein complexes which enhance release from the food matrix (Veda and others 2006; Failla and others 2009; Aherne and others 2010). However, cooking enhanced the bioaccessibility and bioavailability of all-trans $\beta$-carotene but also caused carotenoid isomerization (Aherne and others 2010).

There are many reports describing that thermal processing improves lycopene bioaccessibility due to the breakdown of the tomato matrix (Gartner and others 1997; Porrini and others 1998; Van Het Hof and others 2000). However, depending on the processing methods, differences in lycopene bioaccessibility have been reported. Karakaya and Yilmaz (2007) reported that lycopene bioaccessibility in raw tomato (29\%) and canned tomato $(22 \%)$ was similar. On the other hand, the bioaccessibility of lycopene from sun-dried tomatoes reached 58\% (Karakaya and Yilmaz (2007). High-pressure homogenization (HPH) and $\mathrm{HPH}$ combined with heat processing $\left(90{ }^{\circ} \mathrm{C}\right.$ for $\left.30 \mathrm{~min}\right)$ caused a decrease in the in vitro bioaccessibility of lycopene. In addition, an inverse relationship between the homogenization pressure and lycopene in vitro bioaccessibility was reported (Colle and others 2010). It was suggested that the fiber network formed by HPHentrapped lycopene is not so accessible to digestive enzymes and bile salts. High-pressure processing (HPP), however, had no effect on $\alpha$-carotene and $\beta$-carotene bioaccessibility in carrots. In green beans, lutein bioaccessibility was increased by a pressure treatment at $600 \mathrm{MPa}$ while for $\beta$-carotene, an HPP treatment, either at 400 or $600 \mathrm{MPa}$, reduced its bioaccessibility (McInerney and others 2007), which suggests effects due to the matrix and compound structure.

In wheat bran, ferulic acid and para-coumaric acid are mostly bound to arabinoxylans and lignin and are thus insoluble, whereas sinapic acid is mainly found in soluble conjugate forms esterified to sugars and other compounds. It was reported that the bioaccessibility of sinapic acid from bran-rich breads was much higher than that of ferulic acid and para-coumaric acid (Hemery and others 2010). Food processing, especially grinding of the bran fractions, increased the bioaccessibility of phenolic acids (Hemery and others 2010). Increased bioaccessibility was correlated to the presence of very small particles (diameter $<20 \mu \mathrm{m}$ ) for sinapic acid and ferulic acid and to larger particles for para-coumaric acid (between 20 and $100 \mu \mathrm{m})$. Additionally to particle size reduction, exogenous ferulase and xylanase treatments contributed to the pool of free and exposed ferulic acid residues as demonstrated by the increased antioxidant capacity displayed by treated fractions in an in vitro model of digestion (Rosa and others 2013a, 2013b).

\section{Impact of starting meal size}

Adjustment of the ratio of the amount of the test meal to water present in order to mimic dietary bolus during digestion phases has an impact on viscosity. This ratio, along with particle size, are important factors influencing phytochemical release during digestion.

During transit in the oral cavity, the stomach, and the small intestinal compartments, the dietary bolus will be diluted as a consequence of addition of saliva and other secretions. The amount and type of food influence the composition and secretion rates. Apart from the volume and composition of the secretions, mechanical forces will also have an impact on the disintegration and dissolution of a meal and on the rate of transfer through the GI tract. In general, dynamic models are able to process complex foods through mechanical and enzymatic digestions at volumes equivalent to "standard" meals.

\section{Digestion Models for Studying Phytochemical Bioaccessibility - Static Compared with Dynamic Models}

Depending on the type of research question, for example, if constituting a screening application or a confirmative study, the type and amount of sample present, static or dynamic in vitro models can be used to simulate different phases of digestion (Figure 1). Practically, static models provide a feasible and inexpensive means to assess multiple experimental conditions, allowing large numbers of samples to be tested. Dynamic multistage continuous models facilitate long-term studies and probably come closest to in vivo conditions. These complex computer-controlled systems, however, are expensive to set up, more labor intense and time consuming (maximum 1 experiment/d), and require higher operating costs in terms of working volumes and continuous addition of substances mimicking GI fluids.

\section{Static models}

The simulation of the digestive process can be divided into 2 major stages: simulating gastric and small intestinal digestions, with conditions generally based on the method described by Miller and others (1981). Adaptations to this model have been made to modify the conditions and the procedures for studies of digestibility and bioaccessibility of phytochemicals, but the "physiological conditions" chosen vary considerably across different static in vitro studies.

The comparative simplicity of static methods have allowed their adaptation to measuring the bioaccessibility of many phytochemicals from various fruits and vegetables, including phytosterols (Bohn and others 2007), glucosinolates (Iori and others 2004), carotenoids (Garret and others 1999; Failla and others 2008b), and many types of polyphenols (Gil-Izquierdo and others 2002). This simplicity allows the running of multiple samples in parallel. However, contrary to dynamic models, these static models cannot take into account dynamic physiological responses to the introduction of a food bolus, such as $\mathrm{pH}$ increase and following decrease in the stomach, and enzyme secretions in response to the food bolus introduced (Isenman and others 1999).

However, adaptations of the static model have been carried out for the investigation of various phytochemicals, such as ultracentrifugation and/or filtration, to study the micellar phase of lipophilic constituents. While this is normally not done for polyphenol bioaccessibility, additional steps such as dialysis have occasionally been introduced (Bouayed and others 2012). 


\section{Dynamic models}

Compared to static models, dynamic models have the advantage that they can simulate the continuous changes of the physicochemical conditions including variation of $\mathrm{pH}$ from the mouth to the stomach and the intestine, altering enzyme secretion concentrations, and peristaltic forces in the GI tract.

Different dynamic gastric models (DGMs) have been developed and designed for detailed measurement of gastric biochemistry and mixing. Due to their closer resemblance to in vivo conditions, but much lower throughput, they are more suitable to confirm results obtained in static models and to gain more detailed insights into changes occurring during digestion. The DGM, developed at the Inst. of Food Research (Norwich, U.K.), is composed of 2 successive compartments (Vardakou and others 2011). The model reproduces gastric emptying and secretion according to data derived from echo-planar magnetic resonance imaging and the rates of GI digestion obtained from human studies (Golding and Wooster 2010). The system was originally constructed to assess the impact of the 1st stages of digestion on the bioaccessibility and delivery profiles of nutrients to the duodenum. It simulates the physical mixing, transit, and breakdown forces (including flow, shear, and hydration), $\mathrm{pH}$ gradients, and gastric secretions.

The human gastric simulator (HGS), a model developed at the Univ. of California-Davis is composed of a latex chamber surrounded by a mechanical driving system to effectively mimic the frequency and intensity of the peristaltic movements in the stomach (Kong and Singh 2010). HGS is designed to mimic the gastric shear forces and stomach grinding. This appears to be important for bioaccessibility studies as the rate of release of phytochemicals, from fibrous particles, into the surrounding intestinal fluid is inversely proportional to particle size and directly proportional to phytochemical gradient. It is furthermore affected by the physical state of the phytochemical, the physical structure, and the surface properties of the particle (Palafox-Carlos and others 2011). To allow closer simulation of in vivo physiological processes occurring within the lumen of the stomach and small intestine, some of the main parameters of digestion (such as peristaltic mixing and transit, secretions, and $\mathrm{pH}$ changes) have been applied in some models. The TNO gastrointestinal model (TIM-1) developed by TNO in Zeist (the Netherlands), has been used for a broad range of studies (Minekus and others 1995). The system consists of 4 different compartments, representing the stomach, duodenal, jejunal, and ileal parts of the GI tract. Each compartment is composed of 2 glass jackets lined with flexible walls. The TIM-1 system enables simulation of gastric emptying rate, peristaltic movements, and transit time through the small intestine and gradual $\mathrm{pH}$ changes in the different compartments (Minekus and others 1995). This has given useful information on the parameters affecting the release and digestive stability of carotenoids from different food matrices through the GI tract (Blanquet-Diot and others 2009). This model has also been extensively used to assess both folate and folic acid bioaccessibility from foods (Öhrvik 2008; Öhrvik and others 2010).

For polyphenols, there is limited evidence as to which method is the most appropriate for measuring bioaccessibility, especially as it has become clear that the colon is greatly involved in the metabolism and absorption of these compounds (Bolca and others 2012; Czank and others 2013; Ludwig and others 2013; Pimpão and others 2014). Thus, both static and dynamic models, which do not take into account the simulation of the colon, have limitations in predicting the bioavailability of polyphenols. However, with the development of additional models aiming to simulate colonic fermentation, such as the TIM-2 model, the nonbioaccessible fraction following gastric and small intestinal digestion may be studied, as demonstrated for phenolic compounds in wheat bread (Mateo Anson and others 2009).

An adapted model of TIM-1, a computer-controlled GI model called Tiny-TIM, has more recently been used to assess the bioaccessibility of phenolic acids in breads (Hemery and others 2010). The model is a simplified and downscaled TIM-1 for rapid screening. The main characteristics of the system are the same as for TIM-1, but instead of 4 compartments, the Tiny-TIM model consists of 2 compartments that represent the stomach and the small intestine. The results were found to be consistent both with the data from a previous study evaluating the bioaccessibility of phenolic acids in TIM-1 (Kern and others 2003) and a human study (Mateo Anson and others 2009). To our knowledge, except for the comparison between the results obtained in the TIM-1 and Tiny-Tim models, so far no comparisons between the different dynamic models have been made.

\section{Setting Up the Model \\ Simulation of the oral phase}

The oral cavity is the portal of entry of nutrients and has been considered a "bioreactor" (Gorelik and others 2008; Mathes and others 2010; Ginsburg and others 2012). Saliva is constituted by more than $99 \%$ water, being a very dilute fluid. It contains a variety of minerals, various proteins (the major being the mucin glycoproteins, albumin, and digestive enzymes), and nitrogenous compounds such as urea and ammonia (Ginsburg and others 2012). An intensive mixing of simulated saliva and the introduced food bolus is usually desired, typically in a ratio of 1:1, keeping in mind practicality and the basal flow of saliva during ingestion, estimated at 1 to $3 \mathrm{~mL} / \mathrm{min}$ (Engelen and others 2003). An ingested food or beverage undergoes a number of chemical, biochemical, and mechanical processes in the mouth, although this is less significant for liquids due to short residence time. Components may be subject to changes in $\mathrm{pH}$, ionic strength, and temperature, action of various digestive enzymes (notably lingual lipase, amylase, protease); interactions with biopolymers in the saliva (mucin); interactions with sensory receptors of the tongue and mouth; and particle size reduction of bolus by chewing (mastication). These are all major factors to take into consideration when designing an in vitro digestion step that simulates the human mouth (McClements and $\mathrm{Li}$ 2010).

Particle size reduction. A few studies have paid attention to how mechanical breakdown during the oral phase affects phytochemical bioaccessibility. Mastication consists of grinding food into smaller pieces and imbuing them with saliva, this constitutes the bolus that will be swallowed. By increasing the surface area of hydration and accessability to the action of digestive enzymes, overall digestion efficiency and GI absorption of phytochemicals will increase (Kulp and others 2003). A partial and short chewing of vegetables might influene the availability of major phytochemicals present. However, the interindividual variability in the particle size of food boluses at the end of chewing has been considered to be insignificant for overall bioaccessibility (Woda and others 2010), and the use of 1 individual to chew the meal and expectorate it prior to swallowing was found to be acceptable (Ballance and others 2013). However, further studies are needed to confirm that 1 subject is a practice acceptable for investigating the effect of mechanical breakdown on phytochemical bioaccessibility during the oral phase. When studying bioaccessibility of carotenoids, 
techniques such as grinding or homogenizing, with a stomacher laboratory blender for different intervals in the presence of artificial saliva, were compared with physically masticated foods by humans (Lemmens and others 2010). The average particle size distribution after human chewing was investigated and this information was used to simulate average mastication in vitro by a blending technique.

To produce food boluses with properties similar to those resulting after natural chewing, the Artificial Masticatory Advanced machine (AM2) has been developed and validated against human subjects chewing raw carrots (cylindrical sample height $1 \mathrm{~cm}$, diameter $2 \mathrm{~cm}, 4 \mathrm{~g})$ and peanuts $(3.5 \mathrm{~g}$ ) (Mishellany-Dutour and others 2011). It was concluded that AM2 produces a food bolus with similar granulometric characteristics to human chewing, although no bioaccessibility parameters for phytochemicals were evaluated.

Chemical and biochemical processes. Due to the usually very short interaction of oral enzymes with the food bolus prior to reaching the stomach, their influence is much less clear and rather limited to carbohydrate-rich foods such as cereal-based foods (Hur and others 2011). For example, it is estimated that nearly 5\% of the consumed starch is already degraded in the mouth cavity by salivary amylase (Guyton and Hall 1996). Usually, in vitro methods are initiated using $\alpha$-amylase at $\mathrm{pH}$ around 7 (Table 1).

Ginsburg and others (2012) suggested an important role of saliva in the solubilization of polyphenols present in fruits and plant beverages which substantially increases their availability. Moreover, saliva can enhance adherence of polyphenols to oral surfaces, prolong retention in the oral cavity, and thus contributes to the enhancement of the redox status of the oral cavity. Salivary albumin, mucins, and proline-rich proteins may be of particular importance, affecting the digestibility and absorption of specific polyphenols, for example, tannins may be precipitated by such proteins (Bennick 2002) through hydrogen bonding and hydrophobic interactions.

In summary, an oral digestion phase is recommended for carbohydrate-rich foods. Alternatively, starting with particles of small size (50 to $1000 \mu \mathrm{m}$ ) may be appropriate, as this mimics the particle size following the chewing process for vegetables and fruits (Hoebler and others 2000; Lemmens and others 2010). If oral digestion is omitted, dry samples may be introduced at a ratio of approximately 1:4 (food:liquid), considering common meal sizes of approximately 200 to $300 \mathrm{~g}$ and a gastric juice volume of about $1 \mathrm{~L}$ (Sergent and others 2009). A fluid of physiological salt concentration (such as saline) should be employed.

\section{Simulation of the gastric phase}

The knowledge of disintegration of food inside the stomach is crucial for assessing the bioaccessibility of phytochemicals for both static and dynamic methods. Food disintegration in the stomach is a complex process including mechanical actions and activity of gastric fluids.

Gastric juice contains hydrochloric acid $(\mathrm{HCl})$, pepsinogens, lipase, mucus, electrolytes, and water. The rate of secretion varies from approximately 1 to $4 \mathrm{~mL} / \mathrm{min}$ under fasting conditions to between 1 and $10 \mathrm{~mL} / \mathrm{min}$ after food intake (Wisen and Johansson 1992; Brunner and others 1995). The presence of $\mathrm{HCl}$ contributes to the denaturation of proteins and it activates pepsin.

Peristaltic waves originating from the stomach participate to the size reduction of solid foods down to a diameter of 1 to $2 \mathrm{~mm}$ (Kong and Singh 2010). Stomach emptying is a critical step in the digestion process. Several factors may influence the gastric emptying of food and fluids including volume, viscosity, and $\mathrm{pH}$. The speed of the emptying of liquid meals is directly proportional to the volume present in the stomach. Solid foods are emptied more slowly, in a biphasic pattern with a lag phase during which little emptying occurs, followed by a linear emptying. The duration depends on the physical properties and approximately 3 to $4 \mathrm{~h}$ are needed for a complete emptying of the stomach (Schulze 2006).

A nutrient-driven feedback regulation from the small intestine, limiting the gastric emptying to a maximum of about $3 \mathrm{kcal} / \mathrm{min}$ has been suggested (Lin and others 2005; Kwiatek and others 2009), while other data point to a nutrient-dependent emptying pattern with emulsified fat emptying faster than glucose and proteins (Goetze and others 2007). Furthermore, the presence of dietary fibers is known to slow down gastric emptying of complex meals (Marciani and others 2001).

$\mathrm{pH}$. The gastric $\mathrm{pH}$ in the fasted state in healthy human subjects is in the range of 1.3 to 2.5 . The intake of a meal generally increases the $\mathrm{pH}$ to above 4.5 depending on the buffering capacity of the food. For example, in nasogastrically intubated humans fed a western-type diet enriched in either tomato, or spinach or carrot purees, the stomach $\mathrm{pH}$ sharply increased to approximately 5.4 to 6.2 after meal intake, then continuously decreased to reach approximately 1.8 to 2.9 after $3 \mathrm{~h}$ of digestion (Tyssandier and others 2003).Similarly, after ingestion of a cocoa beverage, the gastric $\mathrm{pH}$ reached 5.4 within $3 \mathrm{~min}$ before returning to the baseline $\mathrm{pH}$ of 1.9 (Rios and others 2002). Most static in vitro studies have been conducted at a $\mathrm{pH}$ below 2.5, which are conditions related to the human fasting state rather than to real food digestion. Only a few authors have considered as relevant a $\mathrm{pH}$ of 4 associated with the midstep of digestion (Reboul and others 2006; Dhuique-Mayer and others 2007). The change of gastric $\mathrm{pH}$ is, however, taken into consideration in $\mathrm{dy}$ namic models as shown for the digestion of tomato carotenoids in the TIM system (pH 6 to 1.6) (Blanquet-Diot and others 2009).

Enzymes. Pepsin, which is readily available as porcine pepsin, has been integrated in most in vitro models of gastric digestion, although in varying amounts (Table 2). Pepsin content should be assessed as enzymatic activity per weight of protein for the sake of comparison. Gastric lipase is usually omitted even though lipolysis in the human stomach by gastric lipase is known (Carriere and others 1993; Armand and others 1994). Most of the lipids from diet are present as emulsified droplets, with diameters in the range of 20 to $40 \mu \mathrm{m}$, and it was suggested that gastric lipolysis can help to increase emulsification in the stomach (Armand and others 1994), which would thus enhance lipophilic phytochemical bioaccessibility. Human gastric lipase secretion ranged from 10 to $25 \mathrm{mg} / 3 \mathrm{~h}$ and the percentage of intragastric lipolysis during gastric digestion was 5\% to 40\% (Carriere and others 1993; Armand 2007) and primarily occured within the 1 st $\mathrm{h}$ of digestion (Armand and others 1994).

Because human gastric lipase is unavailable, fungal lipases from Aspergillus niger or Aspergillus oryzae have been used, as in the TIM model. However, $A$. niger lipase has a wide $\mathrm{pH}$ optimum of 2.5 to 5.5 compared to 4.5 to 6 for human gastric lipase (Carriere and others 1993). The fungal lipase can hydrolyze both the sn-1 and sn3 positions of the triacylglycerol molecule, with a slight preference for the sn-1 position, whereas gastric lipase is most active at the sn3 position (Van Aken and others 2011). Alternatively, a mammalian lipase such as rabbit gastric lipase could be used as Capolino and others (2011) demonstrated that its specificity is close to that of human lipase. At the present time, a combination of rabbit gastric 
Table 1-Concentrations of enzymes and concentrations employed during the oral phase of in vitro (A) and human studies in vivo (B) studies.

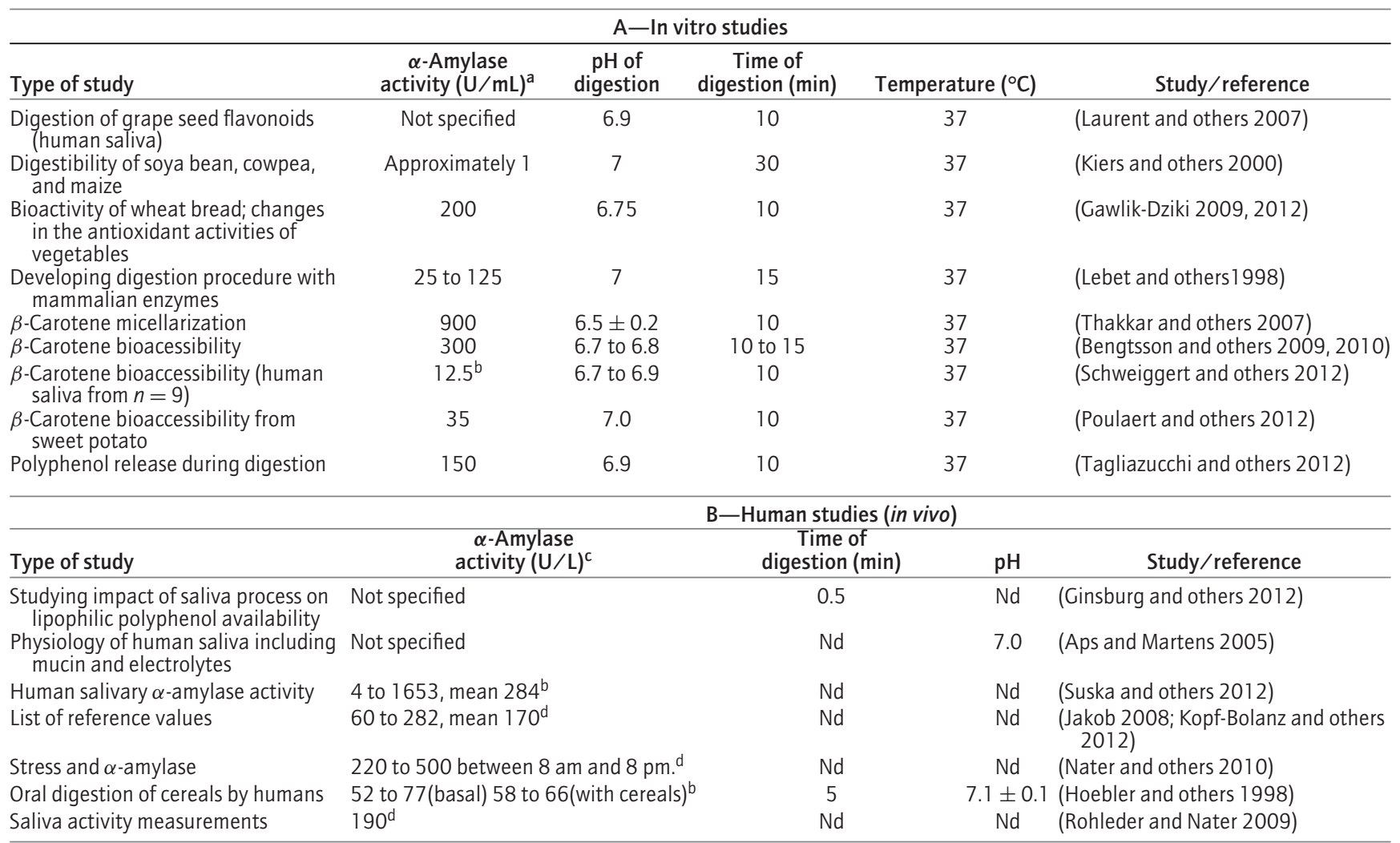

a "Sigma units," unless stated otherwise: 1 unit will liberate $1 \mathrm{mg}$ maltose from starch in $3 \mathrm{~min}$ at $20{ }^{\circ} \mathrm{C}$ at pH 6.9. Often done via the dinitrosalicylic acid (DNS) color assay (540 nm). Conversion to IFCC and Phabedas: when substrate is expressed as same mass unit (mmol not $\mathrm{mg}$ ), 1 DNS unit = approximately 2.5 IFCC units (Bassinello and others 2002 ). For results given in mg, conversion factor from DNS to IFCC is Phabedas: when substrate is expressed as same mass unit ( $\mathrm{mmol}$ not $\mathrm{mg}$ ), 1 DNS unit = approximately 2.5 IFCC units (Bassinello and others 2002 ). For results given in mg, conversion factor from DNS to IFCC is
$\times 2.5 / 342=\times 0.0073$.

files/document/Instructions_Phadebas_Amylase_Test.pdf, $60 \mathrm{U}=1 \mu \mathrm{kat}$

${ }^{c}$ Units are expressed here in final volume of salivary fluid. One unit will cleave $1 \mu$ mol glucosidic linkage from starch per minute, however substrate may differ. Both methods presented here (IFCC EPS [ethylene protected substrate] and Phabedas) yield comparable results

${ }^{d}$ Releases $1 \mu \mathrm{mol} / \mathrm{min}$ p-nitrophenol from 4,6-ethyliden-G7-p-nitrophenol-D-maltoheptasoid (ethylidene-G7PNP), measured at $405 \mathrm{~nm} .60 \mathrm{U}=1 \mu \mathrm{kat}$ [IFCC EPS method]) $\mathrm{Nd}$, no data.

lipase and porcine pancreatic extract is favored to simulate GI lipolysis in vitro.

Oxygen, dietary iron, and antioxidant activity of phytochemicals and micronutrients. The presence of other food components may alter polyphenol and carotenoid stability in the gastric tract. After food intake, lipid oxidation may occur due to the close contact between dietary iron, dioxygen, and emulsified lipids. This was demonstrated for heme (metmyoglobin) and nonheme iron $\left(\mathrm{Fe}^{\mathrm{II}} / \mathrm{Fe}^{\mathrm{III}}\right)$ forms in emulsion systems modeling the physical state of triacylglycerols (Lorrain and others 2012). Dietary polyphenols such as rutin, (+)-catechin, and chlorogenic acid proved to be better inhibitors of the metmyoglobin-initiated lipid oxidation than $\alpha$-tocopherol and vitamin C (Lorrain and others 2010). The antioxidant activity of polyphenols depended on an emulsifying agent (for example, proteins, phospholipids) and $\mathrm{pH}$. In this process, polyphenols were consumed, giving rise to oxidation products which themselves retained antioxidant properties (Lorrain and others 2010). Lycopene and $\beta$-carotene proved to be less efficient inhibitors of lipid oxidation compared to bacterial carotenoids (mainly glycosylated apolycopenoids) (Sy and others 2012b). Phenolic compounds and carotenoids had complementary mechanisms of action: the former inhibited the initiation step of lipid peroxidation by reducing the prooxidative $\mathrm{Fe}^{\mathrm{IV}}$ species of myoglobin while the latter inhibited the propagation phase by direct scavenging of the lipid peroxyl radicals. Oxygen may thus impact phytochemical and micronutrient stability in the gastric tract. The level of dissolved $\mathrm{O}_{2}$ increases during mastication of food (Gorelik and others 2005) but the oxygen partial pressure gradient dropped markedly from the proximal to the distal GI tract in living mice from 58 torr in the midstomach, 32 torr in the midduodenum, 11 torr in the midsmall intestine and midcolon to 3 torr in the distal sigmoid colon-rectal junction (compared to 160 torr for $\mathrm{O}_{2}$ in air) (He and others 1999). For this reason, some authors suggested flushing with nitrogen or argon for a few minutes to reduce the levels of dissolved $\mathrm{O}_{2}$ prior to initiation of simuated digestion (Bermudez-Soto and others 2007).

Static models. Static modeling of gastricdigestion of phytochemicals is basically conducted by a pepsin hydrolysis of homogenized samples under fixed $\mathrm{pH}$ and temperature for a period of time. The internal body temperature $\left(37^{\circ} \mathrm{C}\right)$ is generally used. Dynamic processes occurring during human digestion such as mechanical forces or continuous changes in $\mathrm{pH}$ and secretion flow rates are usually not reproduced (Guerra and others 2012). There are many studies on in vitro digestion of phytochemicals using static models, differing to some extent (Table 2). The major differences among the methods used for modeling the gastric phase of digestion are (1) addition or absence of phospholipid vesicles; (2) addition or absence of lipase; (3) incubation time between 0.5 and $2 \mathrm{~h}$; (4) $\mathrm{pH}$ varying from 1.7 to 2.5 ; and (5) pepsin to substrate ratio.

For highly processed plant matrices, it appears that the large majority of polyphenols is already released in the gastric phase. 
Table 2-Typical concentrations of gastric enzymes in human studies and in vitro experiments.

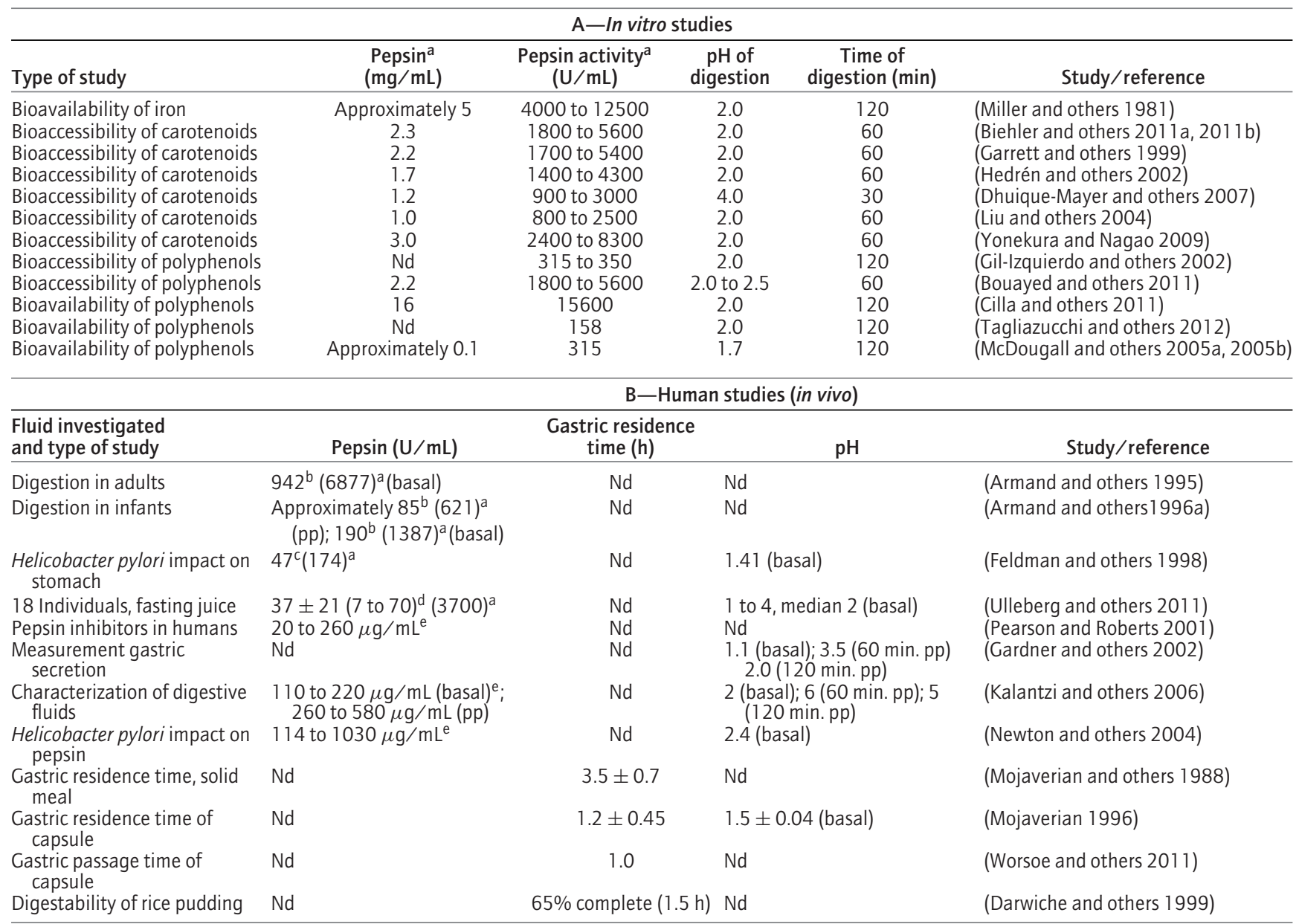

a "Sigma units," pepsin typically used: 800 to 2500 units/mg such as by Sigma-Aldrich. One unit will produce a change in absorbance of 0.001 at $280 \mathrm{~nm}$ at $37{ }^{\circ} \mathrm{C}$, in $1 \mathrm{~min}$, at pH 2.0 , with hemoglobin as substrate. ${ }^{b}$ One pepsin unit has been defined as the amount of enzyme required to produce an absorption of 0.073 at $37^{\circ} \mathrm{C}$ in $10 \mathrm{~min}$ at $\mathrm{pH} 1.8$ from a $2 \%$ hemoglobin solution. One unit equivalent to approximately 7.3

"Sigma units" based on Armand and others (1995), assuming a specific absorption coefficient of tyrosine of $1250(\mathrm{l} / \mathrm{Imol} \times \mathrm{mm}])$.
cMeasured as international units, with $1 \mathrm{IU}=3.7$ Anson units.

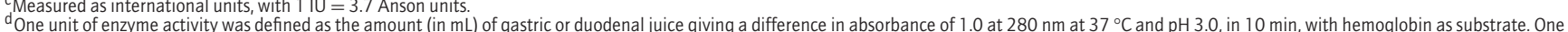
unit equivalent to approximately 100 "Sigma units."

Nd, no data; pp, postprandial; min.pp, minutes postprandial.

Indeed, polyphenol bioaccessibility from fruit juices, wines, green tea, or phenolic extracts, in the presence of simulated gastric juices ( $\mathrm{pH} 1.7$ to 2.5 , pepsin, 1 to $4 \mathrm{~h}$ ) was nearly $100 \%$ (Perez-Vicente and others 2002; McDougall and others 2005a; McDougall and others 2005b; Bermudez-Soto and others 2007; Green and others 2007; McDougall and others 2007; Gumienna and others 2011) but can be only between 30\% and 100\% from solid matrices such as homogenized peaches, apple, grape berries, cherries, or carob flour (Fazzari and others 2008; Bouayed and others 2011; Ortega and others 2011; Tagliazucchi and others 2012).

Among phenolic compounds, apple flavanols (epicatechin and procyanidin B2), aswell as chokeberry proanthocyanidin oligomers, were more degraded than caffeoylquinic derivatives, flavonols, or anthocyanins. Cocoa proanthocyanidins (trimers to hexamers) and apple procyanidin B2 were shown to undergo depolymerization in a simulated gastric juice $\left(37^{\circ} \mathrm{C}, \mathrm{pH} 1.8\right.$ to 2.0) (Spencer and others 2000; Kahle and others 2011), whereas in vivo, this degradation was not validated, mainly because the stomach $\mathrm{pH}$ increased to 5.4 after the ingestion of the cocoa beverage and progressively decreased to the basal value as the stomach emptied (Rios and others 2002).
Certain epoxycarotenoids, such as violaxanthin and neoxanthin from spinach, were shown to undergo epoxide-furanoid transitions at $\mathrm{pH} 2$ (Biehler and others 2011b). This transformation extent may clearly depend on the gastric acidity and time of exposure.

Dynamic models. DGMs of digestion incorporate (1) mixing of the nonhomogeneous gastric digesta as simulated by peristaltic movements in the HGS model (Kong and Singh 2010), (2) acidification, (3) addition of gastric enzymes, and (4) delivery to the duodenum (Chen and others 2011). Usually, computer-controlled protocols are designed to deliver secretions and chyme (digesta) in the normal physiological range. Dynamic models are described in more detail in the previous section "Digestion models for studying phytochemical bioaccessibillity." Up to now, few studies have been reported for phytochemicals in dynamic models compared to the numerous data in static models. For example, in the TIM1 system, tomato $(E)-\beta$-carotene and $(E)$-lycopene proved to be stable, although the recovery yield was modulated by the tomato matrix (Blanquet-Diot and others 2009). The Tiny TIM-1 system was used to evaluate the bioaccessibility of phenolic acids in breads (Hemery and others 2010). The amount of bioaccessible phenolic 
acids was enhanced by using finer particles in wheat bran-rich breads (Hemery and others 2010).

General considerations. The effective release of the phenolic compounds in the stomach maximizes the potential for absorption in the small intestine. For lipophilic compounds, such as for carotenoids, such comparisons are less meaningful, as the formation and incorporation of the mixed micelles are mostly achieved during the small intestinal stage.

In summary, several major aspects deserve consideration during the gastric digestion, including the limitation of oxygen, either by flushing with inert gasses or by reducing the headspace volume to a minimum, the inclusion of gastric lipase, especially for lipid-soluble compounds, and a sufficient protein degradation capacity to allow release of phytochemicals. An initial low $\mathrm{pH}(<3)$ is not physiological and should be avoided due to nonoptimal functioning of enzymes, especially of lipase.

\section{Simulation of the the small intestinal phase}

After food disintegration in the mouth and stomach, the main enzymatic digestion and absorption of nutrients takes place in the small intestine. After stomach digestion, the acidic chyme is delivered to the small intestine and neutralized with sodium bicarbonate to give an appropriate $\mathrm{pH}$ for enzyme activities. The in vitro small intestinal digestion of phytochemicals generally involves mimicking $\mathrm{pH}$, temperature, time, and pancreatic juice including electrolytes, bile salts, and enzymes.

$\mathrm{pH}$, enzymes, and bile salts. In the fed state, $\mathrm{pH}$ can vary from 5.4 to 7.5 in the duodenum (Tyssandier and others 2003; Kalantzi and others 2006; Clarysse and others 2009), to 5.3 to 8.1 in the jejunum (Lindahl and others 1997; Perez de la Cruz Moreno and others 2006), and up to 7.0 to 7.5 in the ileum (Daugherty and Mrsny 1999) (Table 3).

Pancreatic enzymes, including proteases, amylases, and lipases, act together with other digestive enzymes (such as maltase, lactase, $\alpha$-dextrinase, and peptidases) produced by the brush border [a microvillus membrane at the luminal surface of the small intestine (Holmes and Lobley 1989)], in the breakdown of food constituents.

In vivo, bile salt concentrations were found to be higher in the fed state (3 to $12 \mathrm{mM}$ range) than in the fasted state and variable between duodenum and jejunum (Table 3).

The major differences among the methods are the forms of enzymes (pancreatin or individual enzymes) and biliary acids used (bile salt mixtures, real fresh bile, or individual bile salts) (Table 3). Very few models use individually prepared bile salts and enzymes (including porcine pancreatic lipase, porcine colipase, porcine trypsin, bovine chymotrypsin, and porcine amylase), although this may give better control over enzymatic activity (Mandalari and others 2010). Several studies have reported that the presence of bile salts and pancreatic enzymes is essential for the efficient micellarization of lipophilic compounds (Garrett and others 1999; Hedrén and others 2002; Wright and others 2008; Biehler and others 2011a). In the study by Biehler and others (2011a), carotenoid micellarization from spinach was strongly reduced in the absence of pancreatin and bile salts, while it was not significantly impacted by the omission of pepsin during gastric digestion. Minimal bile salt concentration of $2.4 \mathrm{mg} / \mathrm{mL}$ (about $5 \mathrm{mM}$ ), within the in vivo concentration range, was required for optimal transfer of lutein and $\beta$-carotene from lipid droplets into mixed micelles (Garrett and others 1999; Wang and others 2012). The maximum $\beta$-carotene transfer was obtained at $\mathrm{pH} 6$, which reflects the optimal $\mathrm{pH}$ for the activity of pancreatic lipase, and with a pancreatic lipase concentration of $0.4 \mathrm{mg} / \mathrm{mL}$ (Wang and others 2012). At higher bile salt concentrations, $\beta$-carotene micellarization could depend on the activity of pancreatic colipasedependent lipase (Wright and others 2008). For polyphenols, the hydrophilic forms such as glycosylated flavonols or quinic acid derivatives of hydroxycinnamic acids may readily solubilize in the aqueous phase whilst less soluble flavonoid aglycones or procyanidins may bind to dietary fibers and proteins. A bile salt-dependent micellarization has however been suggested for isoflavone aglycones (Walsh and others 2003). In the intestinal conditions, the bioaccessibility and stability of polyphenols depends mainly on $\mathrm{pH}$. In near neutral conditions and in the presence of oxygen as in most in vitro models, some phenolic compounds may be degraded through nonenzymatic oxidation (Bergmann and others 2009). Examination of specific classes revealed that flavan-3-ols were poorly recovered following the digestion of a grape-orangeapricot juice (Cilla and others 2009) but not in chokeberry juice (Bermudez-Soto and others 2007). Pure (+)-catechin was recovered at only $42 \%$ after incubation with pancreatin (BermudezSoto and others 2007), while (-)-epicatechin and procyanidin B2 from homogenized apple were not recovered after the intestinal step (Bouayed and others 2012). The high affinity of monomeric and oligomeric flavanols for proteins and dietary fibers may also lead to their loss during the solid removal step by centrifugation (Le Bourvellec and Renard 2011). For green tea flavanols, the stability order was epicatechin $>$ epicatechin gallate $>$ epigallocatechin $=$ epigallocatechin gallate, which may reflect the higher oxidizability of the 1,2,3-trihydroxyphenyl moiety compared to the 1,2-dihydroxyphenyl one (Green and others 2007). The recovery of caffeoylquinic acids appears to be more affected by the intestinal step than by the gastric step as observed for apple, a grape-orange-apricot beverage, and red wine (Cilla and others 2009; Gumienna and others 2011; Bouayed and others 2012). Chlorogenic acid (5-caffeoylquinic acid) may autooxidize, although regio-isomerization is a major pathway as described for $p$-coumaroyl- and caffeoylquinic acids by Kahle and others (2011). Anthocyanins appear to be the most sensitive class and may largely disappear in the intestinal step (McDougall and others 2005a, 2005b, 2007; Bermudez-Soto and others 2007; Tagliazucchi and others 2010,2012). The quantification of anthocyanins is complicated by a $\mathrm{pH}$-dependent equilibrium of the red flavylium cation to several related structures at $\mathrm{pH}$ above 2 . The hydration of the flavylium cation produces a colorless hemiketal which is in equilibrium with colorless (E)- and (Z)-chalcone forms. In the near-neutral conditions of intestinal digestion, a 1st deprotonation of the flavylium cation provides neutral quinonoidal bases $(\mathrm{pKa} \approx$ 4), which can further be deprotonated to ionic quinonoidal bases ( $\mathrm{pKa} \approx 6)$, both bases displaying blue and violet hues (Brouillard and others 1991; Clifford 2000). Thus, the detection of anthocyanins in simulated GI conditions can be challenging as it is influenced by $\mathrm{pH}$ and copigment molecules. For example, PerezVicente and others (2012) evaluated the recovery of pomegranate anthocyanins to be $18 \%$ when measured at the $\mathrm{pH}$ of the intestinal digesta and $70 \%$ following acidification of the digesta at $\mathrm{pH} 2$. Analysis of anthocyanins at $\mathrm{pH}$ lower than 2 should be favored as it is more convenient to evaluate the flavylium cation form by high-performance liquid chromatography (HPLC) or colorimetric tests.

When exposed to acids or bases, ester bonds in ellagitannins and in caffeoylquinic acids are hydrolyzed and the ellagitannins yield hexahydroxydiphenic acid which is spontaneously rearranged into the water-insoluble ellagic acid (Clifford and Scalbert 2000). 
Table 3-Concentrations of intestinal enzymes and bile salts in humans studies and in vitro experiments.

\begin{tabular}{|c|c|c|c|c|c|c|}
\hline \multicolumn{7}{|c|}{ A-In vitro studies } \\
\hline $\begin{array}{l}\text { Type } \\
\text { of study }\end{array}$ & $\begin{array}{l}\text { Bile salts }{ }^{\mathrm{a}} \\
(\mathrm{mmol} / \mathrm{L})\end{array}$ & $\begin{array}{c}\text { Pancreatin }^{\mathrm{b}} \\
\text { concentration, } \\
\text { approximately }(\mathrm{mg} / \mathrm{L})\end{array}$ & $\begin{array}{c}\text { Minimum } \\
\text { pancreatin activity } \\
(\mathrm{U} / \mathrm{mL})^{\mathrm{b}}\end{array}$ & $\mathrm{pH}$ & $\begin{array}{l}\text { Digestion } \\
\text { time (min) }\end{array}$ & $\begin{array}{l}\text { Study/ } \\
\text { reference }\end{array}$ \\
\hline $\begin{array}{l}\text { Bioaccessibility of } \\
\text { iron }\end{array}$ & $\begin{array}{c}\text { Approximately } \\
4(2 \mathrm{~g} / \mathrm{L})\end{array}$ & 300 & 2.4 & 7.5 & 150 & (Miller and others 1981) \\
\hline $\begin{array}{l}\text { Bioaccessibility of } \\
\text { carotenoids }\end{array}$ & $\begin{array}{r}\text { Approximately } \\
8.6(4.3 \mathrm{~g} / \mathrm{L})\end{array}$ & 720 & 5.8 & 7 to 7.5 & 120 & (Biehler and others $2011 \mathrm{~b}$ ) \\
\hline $\begin{array}{l}\text { Bioaccessibility of } \\
\text { carotenoids }\end{array}$ & $12(6 \mathrm{~g} / \mathrm{L})$ & 2500 & 20 & 7.5 & 120 & (Yonekura and Nagao 2009) \\
\hline $\begin{array}{l}\text { Bioaccessibility of } \\
\text { carotenoids }\end{array}$ & $4.4(2.1 \mathrm{~g} / \mathrm{L})$ & 390 & 3.1 & 7.5 & 120 & (Garrett and others 1999) \\
\hline $\begin{array}{l}\text { Bioaccessibility of } \\
\text { carotenoids }\end{array}$ & $7.5(3.75 \mathrm{~g} / \mathrm{L})$ & 600 & 4.8 & 7.5 & 30 & (Hedrén and others 2002) \\
\hline $\begin{array}{l}\text { Bioaccessibility of } \\
\text { carotenoids }\end{array}$ & $2.8(1.44 \mathrm{~g} / \mathrm{L})$ & 240 & 2.0 & 6.0 & 30 & $\begin{array}{l}\text { (Dhuique-Mayer and others } \\
\text { 2007) }\end{array}$ \\
\hline $\begin{array}{l}\text { Bioaccessibility of } \\
\text { carotenoids }\end{array}$ & $3.0(1.5 \mathrm{~g} / \mathrm{L})$ & 250 & 2.0 & Approximately 7 & 120 & (Liu and others 2004) \\
\hline $\begin{array}{l}\text { Bioaccessibility of } \\
\text { polyphenols }\end{array}$ & $3.0(1.5 \mathrm{~g} / \mathrm{L})$ & 250 & 2.0 & 5 to 7.5 & 120 & $\begin{array}{l}\text { (Gil-Izquierdo and others } \\
\text { 2002) }\end{array}$ \\
\hline $\begin{array}{l}\text { Bioaccessibility of } \\
\text { polyphenols }\end{array}$ & $4.3(2.2 \mathrm{~g} / \mathrm{L})$ & 360 & 2.9 & $6.5 \rightarrow 7.0$ to 7.5 & 165 & (Bouayed and others 2011) \\
\hline $\begin{array}{l}\text { Bioaccessibility of } \\
\text { polyphenols }\end{array}$ & $44(22 \mathrm{~g} / \mathrm{L})$ & 3600 & 29 & 6.5 & 120 & (Cilla and others 2011) \\
\hline $\begin{array}{l}\text { Bioaccessibility of } \\
\text { polyphenols }\end{array}$ & $10(5 \mathrm{~g} / \mathrm{L})$ & 800 & 6.4 & 7.5 & 120 & $\begin{array}{l}\text { (Tagliazucchi and others } \\
\text { 2012) }\end{array}$ \\
\hline $\begin{array}{l}\text { Bioavailability of } \\
\text { polyphenols }\end{array}$ & $10(5 \mathrm{~g} / \mathrm{L})$ & 800 & 6.4 & $\mathrm{Nd}$ & 120 & $\begin{array}{l}\text { (McDougall and others } \\
\text { 2005a, 2005b) }\end{array}$ \\
\hline
\end{tabular}

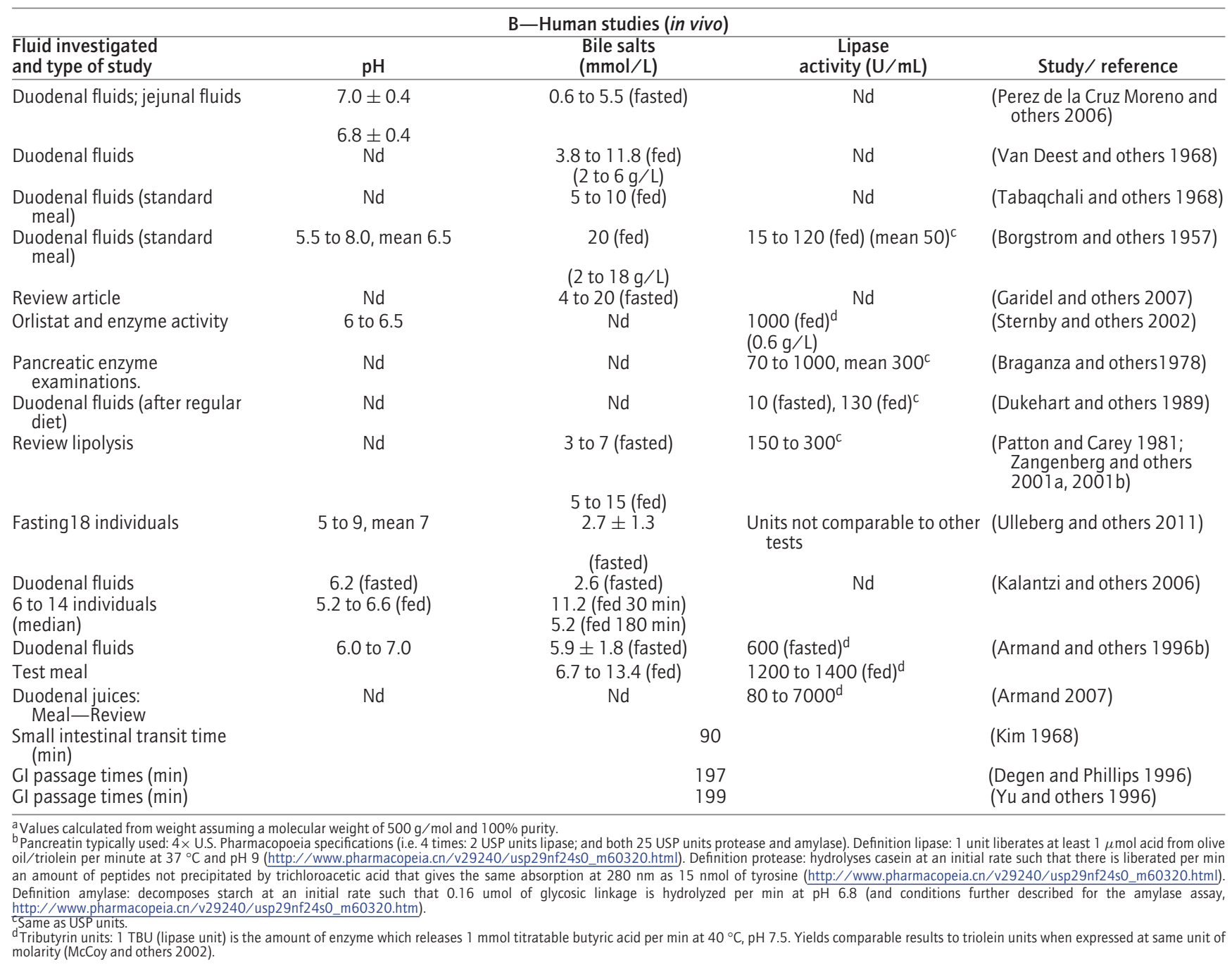


Daniel and others (1991) showed that ellagic acid could be released from raspberry ellagitannins at $\mathrm{pH} 7$ and optimally at $\mathrm{pH}$ 8. Furthermore, Gil-Izquierdo and others (2002) observed a 5 - to 10-fold increase in ellagic acid from strawberry ellagitannins during incubation with pancreatic enzymes in mild alkaline conditions (Gil-Izquierdo and others 2002). This may be the mechanism behind the relative increases in smaller ellagitannin molecules noted during in vitro digestion of raspberry and strawberry extracts (McDougall and others 2007; Brown and others 2012). In the mildly alkaline conditions of in vitro digestion, orange flavanones rearrange to form less soluble chalcone forms which can precipitate (Gil-Izquierdo and others 2003). However, more than $90 \%$ of orange flavanones and $80 \%$ of soy isoflavone glycosides were recovered after the intestinal step, outlining their high stability toward autoxidation (Gil-Izquierdo and others 2003; Walsh and others 2003). The sensitivity to autoxidation is probably overestimated in in vitro digestion models as oxygen levels are lower in the GI tract. Last, it should be noted that proteolytic enzymes could play a role in polyphenol bioaccessibility by releasing phenolic compounds bound to dietary proteins as observed in the gastric tract for pepsin. However, more data support a role for phenolic compounds as inhibitors of intestinal enzymes such as trypsin and lipase (He and others 2006; Gonçalves and others 2007).

Static models. Conditions used in in vitro static models simulate quite well the physiology of intestinal digestion with the use of porcine pancreatin, biliary extract or bile salts, and a $\mathrm{pH}$ ranging between 6.0 and 7.5 (Table 3). However, the time allowed for this step is highly variable $(0.5$ to $2.5 \mathrm{~h})$. A too short digestion time may lead to trapping of carotenoids in triglycerides, and thus underestimate carotenoid bioaccessibility (Sy and others 2012a). Different carotenoids show differing micellarization. Xanthophylls (lutein and $\beta$-cryptoxanthin) showed higher micellarization compared to $\alpha$ - and $\beta$-carotenes, while lycopene was only slightly micellarized (Garrett and others 2000; Reboul and others 2006; Thakkar and Failla 2008). There have also been differences noted between (E)-carotenoids and their (Z)-isomers (Chitchumroonchokchai and others 2004; Bengtsson and others 2010), with the latter commonly found in processed foods, also tending to be better micellarized (Bohn 2008). It could also be speculated that a prolonged time of small intestinal digestion will favor the formation of more $\mathrm{Z}$-isomers. However, the in vivo data showed no significant isomerization either in the stomach or in the duodenum for $\beta$-carotene and lycopene (Tyssandier and others 2003).

In many in vitro studies, the stability of phenolic compounds has been assessed by determining total phenolic content such as by the Folin-Ciocalteu method (Singleton and Rossi 1965), which does not yield information on the recovery of specific phenolic classes or molecules. The recovery of total phenol content after the intestinal phase (when compared to the gastric step) was not reduced for homogenized prunes (81\% of the initial content; Tagliazucchi and others 2012), grape berries (62\%; Tagliazucchi and others 2010), cherries (127\%; Fazzari and others 2008), pomegranate juice (100\%; Perez-Vicente and others 2002), and red cabbage extract (100\%; McDougall and others 2007). However, a loss in total phenolics during the intestinal step was observed for plums (44\%), peaches $(37 \%)$, tomatoes (31\%; Tagliazucchi and others 2012), chokeberry juice (73\%; Bermudez-Soto and others 2007), raspberry extract (86\%; McDougall and others 2005b), and red wine (47\% and 58\%; McDougall and others 2005b), many of which contain labile anthocyanins. In conclusion, the analysis of specific phenolic compounds, and their possible degradation prod- ucts, should be addressed to avoid conflicting results. Additionally, findings on the recovery of different classes in 1 fruit/vegetable cannot be readily extended to other sources as stability in vitro is influenced by interactions with the other phenolic compounds in the mixture and with other components such as vitamin $\mathrm{C}$ (for example, through sacrificial oxidation).

Dynamic models. To simulate the in vivo conditions of the small intestine, dynamic models can be used to reproduce $\mathrm{pH}$ changes and secretion of pancreatic juice and bile. In the TIM model, the intestinal transit time and $\mathrm{pH}$ conditions in the human digestive tract are simulated through preprogrammed $\mathrm{pH}$ and delivery curves (Minekus and others 1995). Porcine pancreatin, bile salts, electrolytes, and $\mathrm{NaHCO}_{3}$ are secreted by computer-controlled pumps. The model does not mimic brush border secretions. The $\mathrm{pH}$ is usually increased between the duodenal, jejunal, and ileal compartments, for example, from 6.4 to 7.2 for the digestion of a tomato-containing Western diet (Blanquet-Diot and others 2009). The GI transit time may greatly influence the bioaccessibility of phytochemicals by affecting the release from the food matrix. Additionally, the solubility and stability of different compounds may be affected by the time they are exposed to the conditions in the intestinal tract. Apart from the integration of key parameters of digestion such as transit time, peristaltic mixing, and transport, the ability to remove digested material by passive absorption of water and digested molecules through a dialysis system is also an important feature of in vitro models. In particular, removal of digested molecules may prevent product inhibition of the pancreatic enzymes (Minekus and others 1995).

The TIM-1 and Tiny-TIM systems have been used to study the digestive stability of carotenoids from tomato, and phenolic acids present in bread, respectively (Blanquet-Diot and others 2009; Hemery and others 2010). The TIM-1 system can be equipped with semipermeable hollow fiber membrane filters (with a molecular weight cutoff ranging between 3 and $5 \mathrm{kDa}$ to 5 and $8 \mathrm{kDa}$, depending on filter type) connected to the jejunal and ileal compartments in order to remove degraded compounds and to simulate absorption of water-soluble nutrients. For the estimation of the bioaccessibility of lipophilic carotenoids, the incorporation into micelles is crucial and for this purpose the TIM system must be equipped with a specific membrane that separates the micellar phase from the fat phase (Minekus and others 2005). The presence of fat and bile salts is one of the factors that condition the formation of micelles which should be less than $10 \mathrm{~nm}$ in diameter. Moreover, protocols of digestion must be optimized to ensure triglyceride hydrolysis and micellarization by bile salts.

General considerations. The contribution of the intestinal step to the bioaccessibility of phenolic compounds is clearly influenced by several parameters. First, the action of intestinal enzymes on the residual matrix could increase the phenolic content. Next, phenolic compounds are chemically reactive in near-neutral conditions and their degradation or isomerization may be catalyzed by the presence of oxygen and/or transition-metal ions. Additionally, specific absorption by the small intestine can occur by passive diffusion or active transport, as demonstrated for aglycones and their glucosylated forms. The latter forms can be actively transported by the sodium-glucose-linked transporter 1 (SGLT1) found in the enterocytes. Extracellular hydrolysis can be promoted by lactase phlorizin hydrolase in the brush border and be followed by diffusion of the resulting aglycone into the enterocyte (Day and others 2000). A transcellular transport involving multidrug resistance protein and P-glycoprotein transporters appears to be favored for hydroxycinnamic acid and flavonol aglycones (Poquet 
and Clifford 2008; Barrington and others 2009). These 2 phenomena cannot be readily modeled in vitro. Therefore, in vitro digestion methods may overestimate the levels of these phenolic components.

In summary, limiting oxygen levels; an inclusion of brush border enzymes or other $\alpha$-glucosidase activities; a sufficient bile salt concentration; and the presence of lipolytic, amylolytic, and proteolytic enzymes for specific nutrient digestion are all of importance for an optimal release of phytochemicals. While remaining triglycerides may trap lipid-soluble phytochemicals, incompletely digested proteins and polysaccharides may bind to water-soluble phytochemicals, making them unavailable in the small intestine.

\section{Large intestinal bioconversions}

The colon contains a highly complex microbial ecosystem, which is capable of fermenting food components not digested in the upper GI tract. Some undigested food ingredients, including certain polyphenols, can act as substrate for the indigenous bacterial community (Possemiers and others 2011). In addition, products from microbial bioconversion can affect the intestinal ecosystem and the bioavailability of the parent compounds. Carotenoids are typically not studied in colonic models, as they are primarily absorbed in the small intestine, and colonic metabolites have not been reported so far. Colonic bioconversion of phenolic compounds is most well described for flavonoids, and phytoestrogens, lignans and isoflavonoids (Table 4). The complexity of in vitro colonic models used to study the metabolism of phenolic compounds is diverse, ranging from batch fecal incubations using a strictly anaerobic and dense fecal microbiota suitable for metabolic studies (Barry and others 1995; Gross and others 2010; Aura and others 2012) to more complex continuous models involving 1 or multiple connected, $\mathrm{pH}$-controlled vessels to mimic different parts of the human colon (Fogliano and others 2011) or in vitro dynamic GI-colonic system models (Gao and others 2006 ; Van Dorsten and others 2012), which are applicable also to study effects of food components on the microbial population.

Characterization of phenolic metabolites using in vitro colonic models is complementary to the metabolic bioconversion by the small intestine or the liver (methylation, sulfation, and glucuronidation) of the native forms that are present in foods (Scalbert and others 2002) and shows the diversity of structural transformations occurring in the colon prior to absorption (Aura 2008; Selma and others 2009). Colonic metabolism of phenolic compounds starts with the transient appearance of aglycones and the subsequent formation of hydroxylated aromatic compounds and phenolic acids (Rechner and others 2004; Aura 2008). Flavones, flavanones, flavanols, proanthocyanidins, and phenolic acids share hydroxyphenylpropionic acid metabolites (Rechner and others 2004; Aura 2008), whereas flavonols (quercetin, myricetin) and ferulic acid dimers share hydroxylated phenylacetic acid metabolites (Aura and others 2002; Braune and others 2009). Moreover, flavanols also yield hydroxyphenylvaleric acids and corresponding valerolactone derivatives (Aura and others 2008; Sanchez-Patan and others 2012). Anthocyanins yield benzoic acids, hydroxylated benzaldehydes, and acetaldehydes (Aura and others 2005; Fleschhut and others 2006; Czank and others 2013). Complex microbial metabolites, such as lactones formed from plant lignans or ellagitannins (Heinonen and others 2001; Cerda and others 2004), are reabsorbed from the colon and are subject again to liver metabolism and the conjugate derivatives are excreted via urine (Adlercreutz and others 1995). Thus, plasma and urine excretions reflect both the hepatic and colonic metabolism of polyphenols (Table 4).

Limitations of in vitro colonic models include that they may not fully represent the microbiota present in the colonic lumen and mucosa and that the combined rates of catabolism and absorption that occur in vivo are not reproduced. However, the use of colonic models provides information on the types of microbial metabolites formed (Table 4) and helps to elucidate the pathways involved. Static or batch models are of particular interest for a 1st assessment of colonic metabolism of phenolic compounds, which can be complicated by a high interindividual variability (Gross and others 2010), or for comparison of different sources or doses of compounds (Bolca and others 2009). The anaerobic batch colonic model developed by Barry and others (1995), which uses pooled human feces from several healthy donors, has been particularly suitable when coupled with a metabolomics platform to investigate the effects of structure and dose of fruit proanthocyanidin fractions on the efficiency of microbial metabolism and structure of flavanol monomers (Aura and others 2008; Aura and others 2012).

Dynamic, multicompartment colonic models are useful for long-term experiments needed to evaluate the spatial and temporal adaptation of the colonic microbiota to dietary phenolic compounds and the microbial metabolism of these phytochemicals. These models are designed to and should harbor a reproducible microbial community that should be stable upon inoculation, colon region-specific, and relevant to in vivo conditions (Macfarlane and others 1998; Van den Abbeele and others 2010). Dynamic colonic models have shown that microbial metabolism of black tea and red wine (Van Dorsten and others 2012) and cocoa (Fogliano and others 2011) is dependent on colon location. In addition, dynamic models may be used to enrich the colonic microbiota with polyphenol-converting species such as Eubacterium limosum to increase the production of 8-prenylnaringenin from hop extracts (Possemiers and others 2008). New tools to improve modeling the physiological colonic conditions have been integrated into dynamic systems, such as the incorporation of a mucosal environment (Macfarlane and others 2005; Van den Abbeele and others 2012) and a mucus layer combined with epithelial cells (Marzorati and others 2011). These models can differentiate between the luminal microbiota with a large metabolic degradation capacity and the mucosa-associated microbiota able to closely interact with the host.

An important element to be considered for designing colonic model experiments is the use of 1 or multiple fecal donors in terms of diversity of the microbiota population, as high- and low-polyphenol metabolizing phenotypes can skew the extent of metabolism of certain compounds (Selma and others 2009; Bolca and others 2012). Meanwhile, comparison of human gut metagenomes has suggested the classification of individuals into 3 distinct enterotypes (Arumugam and others 2011). The maintenance of anaerobic conditions during stool processing and inoculation to the models is crucial for microbial and enzymatic activities. Another important matter to be considered is the $\mathrm{pH}$ adjustment needed to avoid suppression of particularly minor conversion activities (for example, slow enterolactone formation (Aura 2008)).

In summary, in vitro colonic models are the preferred choice to study mechanisms of polyphenol microbial metabolism as well as the polyphenol-induced modulation of gut microbiota. However, the ability of colonic models to simulate the in vivo conditions is limited by the lack of studies involving the formation of microbial biofilms adhering to the colonic epithelium. The simulation 


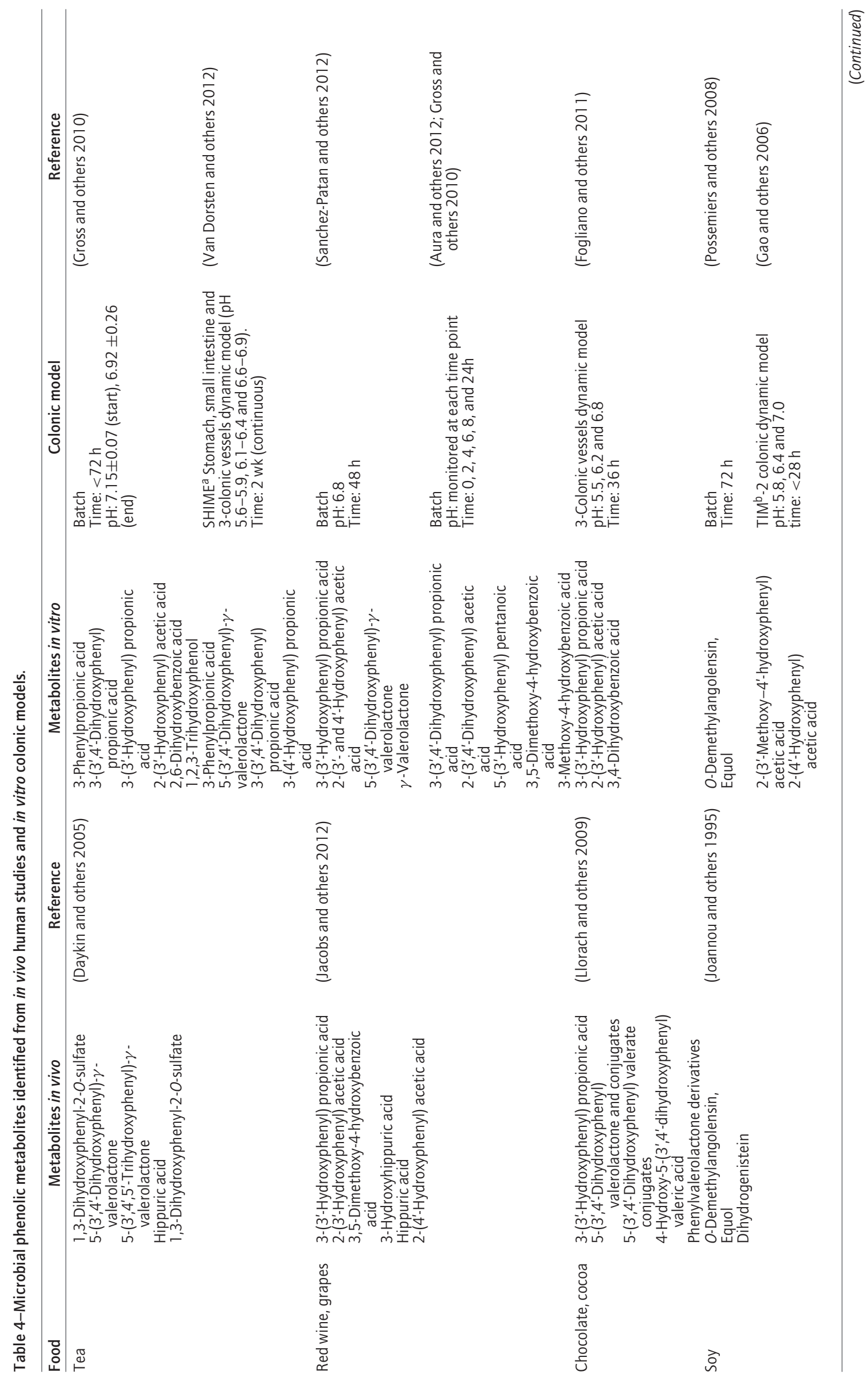




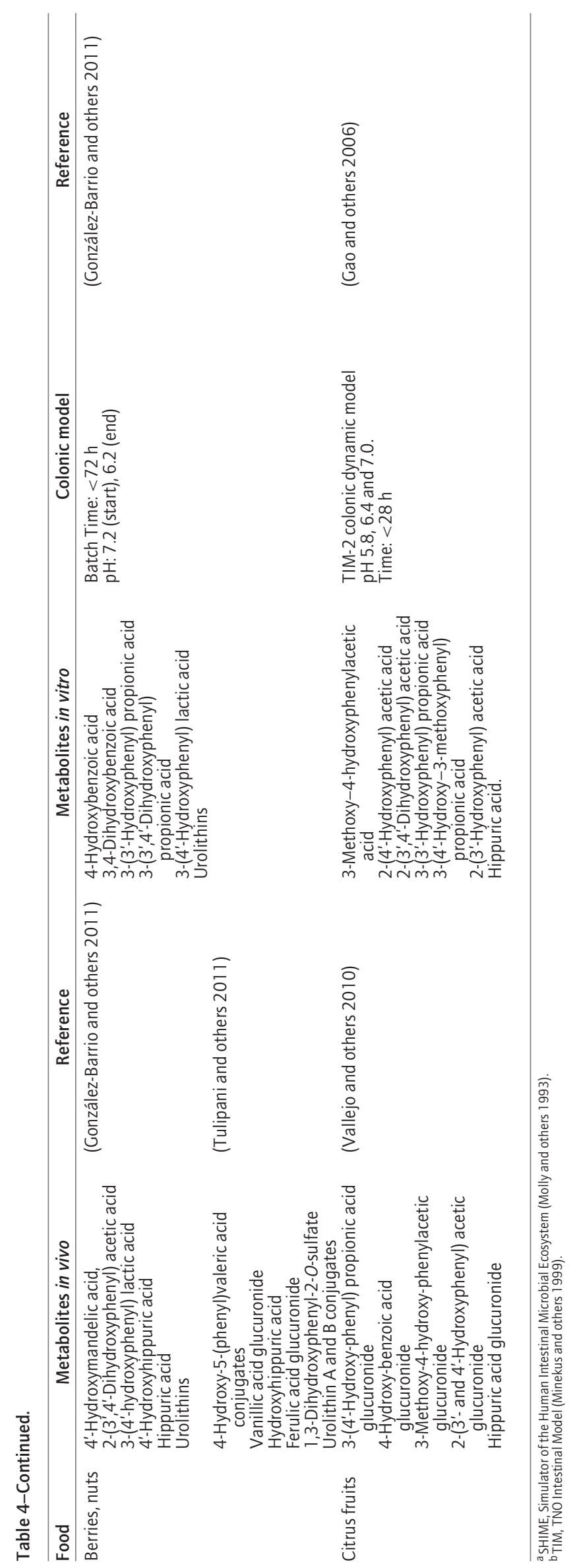


of intestinal absorption to remove end products of microbial metabolism is also relevant to prevent inhibition of the colonic microbiota during in vitro studies.

\section{Determination of bioaccessible fraction and further cou- pling techniques following digestion and/or colonic fermentation}

In vitro digestion model systems either simulate disintegration processes only (for bioaccessibility) or both digestion and absorption processes (for bioavailability estimates). According to the desired end points of the studies, there are considerable differences in the type of experimental parameters measured after digestion. These may include chemical changes (such as hydrolysis of macronutrients), gastric solubilization of drugs, nutrient availability, release of encapsulated components, studying competitive processes, and structural changes (such as breakdown of specific structures), aggregation, droplet coalescence, or droplet disruption (Chen and others 2011). Thus, samples obtained by in vitro digestion, either following small intestinal digestion or following further colonic fermentation in vitro, have been used in a variety of ways. In addition, the obtained fractions have been coupled to further investigation procedures, allowing, for example, the estimation of uptake into or transport through the intestinal epithelium.

Estimation of bioaccessibility. The estimation of the bioaccessibility of nonpolar food constituents such as carotenoids has been made both by measuring the transfer of carotenoids from the food matrix to the aqueous layer obtained after in vitro digestion and centrifugation (Hedrén and others 2002; Bengtsson and others 2009) or by filtering the aqueous fraction through a $0.22-\mu \mathrm{m}$ membrane to obtain mixed micelles (Reboul and others 2006; Huo and others 2007), or both. Since the micellarized carotenoids are considered to be the form in which these compounds will ultimately be absorbed by the intestinal cells, it has been suggested that assessment of carotenoid bioaccessibility must include the isolation, extraction, and measurement of carotenoids in micelles (Etcheverry and others 2012). Reboul and others (2006) showed a high correlation $(r=0.90)$ of the in vitro bioaccessibility of $\alpha$ - and $\gamma$-tocopherol, $\beta$-carotene, and lycopene with the in vivo values measured in the micellar phase from human duodenum during digestion of a carotenoid-rich meal. Their findings suggest that estimation of carotenoid micellarization in vitro can be indicative of the amount available for uptake in the GI tract in vivo.

For polyphenols, Bouayed and others $(2011,2012)$ studied bioaccessibility following simulated gastric and intestinal in vitro digestion of fresh apple. They used a cellulose semipermeable membrane, chosen as a simplified mechanical model for the epithelial barrier to identify dialyzable polyphenols after intestinal digestion. They suggested that dialyzable polyphenols in the intestinal phase could potentially be taken up by the enterocytes and proposed it may be a practical step prior to coupling to cellular methods due to increased purity of the dialysate, preventing negative impacts on cell viability. Similar studies were performed by other researchers (Liang and others 2012; Tavares and others 2012; Rodriguez-Roque and others 2013). At the same time, it is difficult to study the in vivo changes and digestive stability of different food constituents during their passage through the digestive tract, although some approaches, such as studying ileostomists, have allowed some comparisons to in vitro small intestinal digestion (Walsh and others 2007; Erk and others 2012).

Bioaccessibility following colonic fermentation. In vitro digestion procedures have also been employed to produce berry samples that are characteristic of components that survive diges- tion, and therefore are more physiologically relevant, for studies on bioactivities concerning colon cancer models (Brown and others 2012).

Due to the limited sampling possibilities (and intra- and interindividual variations), the function and the composition of ileal microbiota is hard to study in vivo. The effect of small intestinal microbiota on the enzymatic hydrolysis of phenol glycosides was studied in an ex vivo ileostomy model (Knaup and others 2007). Ileostomy effluents from 3 healthy subjects were used for incubation with synthetic quercetin and $p$-nitrophenol glycosides. The conclusion was that the hydrolysis of phenol glycosides is influenced both by the structural components of the phenols and the microbiota in the small intestine. Schantz and others (2010) have also reported evidence of degradation of polyphenols in the small intestine, using an ex vivo ileostomy model to study the microbial metabolism and chemical stability of green tea cathechins and gallic acid. According to studies in ileostomy patients, the ileal microbiota is restored 6 mo after surgery (Mortensen and Clausen 1996), which may resemble the reflux situation occurring in subjects with a healthy colon, or even take the role of colon fermentation to some extent in ileostomy patients.

Phenolic microbial metabolites are relevant in terms of human health because they appear in plasma and are excreted in urine (Aura 2008). Pharmacokinetic studies show that microbial metabolite concentrations are elevated for up to 24 to $48 \mathrm{~h}$ in the bloodstream after a single dose of their precursors before returning to baseline values (Sawai and others 1987; Gross and others 1996; Kuijsten and others 2005). Enterolactone, enterodiol, and urolithins are excreted via urine as hepatic conjugates (Heinonen and others 2001; Cerda and others 2004). Microbial phenolic acid metabolites appear in urine mainly in a free form in contrast to beverage-derived phenolic acids, which are excreted mainly as sulfates and glucuronides (Sawai and others 1987; Stalmach and others 2009). In a recent work, Ludwig and others (2013) have shown that after ingestion of coffee, the main colon-derived metabolites found in plasma and/or in urine were dihydrocaffeic acid, dihydroferulic acid, and their sulfated and glucuronidated metabolites. The metabolites described above and their hepatic conjugates are found in plasma and urine and circulate through the body, and may therefore exhibit both local and systemic effects. Phenolic metabolite levels in plasma range from low to high nano molar concentrations (Sawai and others 1987; Kilkkinen and others 2001; Kern and others 2003; Johnsen and others 2004; Kuijsten and others 2006), whereas urinary levels are at the micromolar range. In peripheral tissues, the concentrations can be anticipated to be even lower.

A good example of studies encompassing in vitro digestion models and colon conversion and pharmacokinetic studies in human volunteers was performed by Mateo Anson and others $(2009,2011)$. The group showed that bioprocessing of wheat bran with enzymes (xylanase, cellulose, $\beta$-glucanase, and feruloyl esterase) and yeast enhanced the bioaccessibility of ferulic acid, para-coumaric acid, and sinapic acid from white wheat bread matrix in the in vitro GI models TIM-1 and TIM- 2 by 5 -fold. Since the release of para-coumaric acid and sinapic acid occurred mainly in the TIM-1 model simulating the upper intestine, the microbial conversion products (3-(3'-hydroxyphenyl) propionic acid and 3phenylpropionic acid) from the TIM-2 colon model were shown to be related to matrix bound ferulic acid (Mateo Anson and others 2009). In a subsequent pharmacokinetic in vivo study, volunteers consumed $300 \mathrm{~g}$ white wheat bread samples fortified with either native or bioprocessed wheat bran, and then phenolic acids and 
Table 5-Summarized parameters for simulated digestion under static conditions, based on common in vitro values applied, feasibility, and their similarity to in vivo conditions.

\begin{tabular}{|c|c|c|c|}
\hline Phase of digestion & Common in vitro values $^{a}$ & Common in vivo values $^{a}$ & Tentatively suggested $^{\mathrm{b}}$ \\
\hline \multicolumn{4}{|l|}{ Oral phase } \\
\hline$\alpha$-Amylase $(\mathrm{U} / \mathrm{mL})^{c}$ & 110 & 26 & 25 to 200 \\
\hline Time (min) & 10 & 0.5 to 5 & 1 to 5 \\
\hline $\mathrm{pH}$ & & $7.1 \pm 0.1$ & $7.0 \pm 0.2$ \\
\hline \multicolumn{4}{|l|}{ Gastric phase } \\
\hline Pepsin $(U / m L){ }^{d}, f$ & 1400 to 4300 & 1400 to $3700 ;$ & 2000 to 10000 \\
\hline Time (min) & 60 & 60 to $72 ; 140$ to $210^{e}$ & $60 ; 120^{e}$ \\
\hline $\mathrm{pH}$ & 2.0 & 2 (fasted); 3.5 (120 min [fed $\left.{ }^{9}\right)$ & $3.5 \pm 0.5$ \\
\hline \multicolumn{4}{|l|}{ Small intestine } \\
\hline Lipase $^{\mathrm{h}}$ & $4.0(0.5 \mathrm{~g} / \mathrm{L})$ & 70 to 1000 (fed); 10 (fasted) & 20 to 200 \\
\hline Bile salts (mmol/L) & $7.5(3.8 \mathrm{~g} / \mathrm{L})$ & 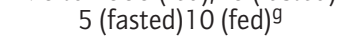 & 10 \\
\hline Time (min) & 120 & 200 & 120 to 200 \\
\hline $\mathrm{pH}$ & 7 to 7.5 & $6.8 \pm 0.4$ & $7 \pm 0.2$ \\
\hline \multicolumn{4}{|l|}{ Large intestine } \\
\hline Time (h) & 42 (24 to 72$)$ & $35 \pm 2.1$ & 35 to 45 \\
\hline $\mathrm{pH}$ & 6.6 (5.5 to 7.2, start) 6.6 (end) & $6.2(5.7$ to 6.7$)$ & 6.2 to 6.6 \\
\hline \multicolumn{4}{|c|}{ 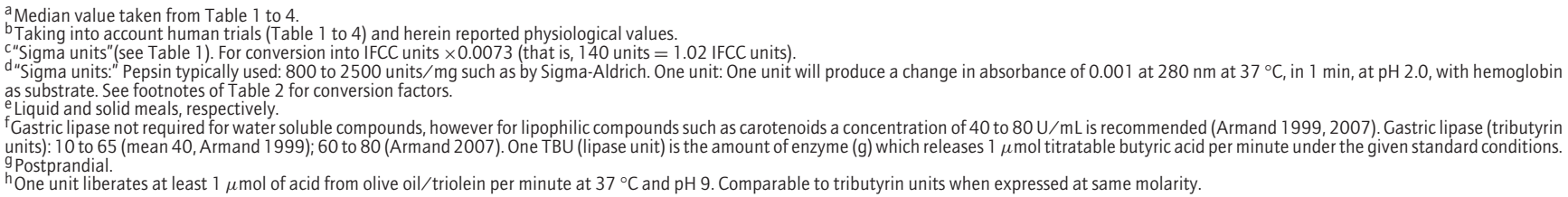 } \\
\hline
\end{tabular}

their metabolites were followed for $24 \mathrm{~h}$. The release and conversion of microbial metabolites were enhanced by bioprocessing of bran by 2 - to 3 -fold and their time course profiles in plasma were altered by bioprocessing of bran (Mateo Anson and others 2011).

Coupling digesta to uptake and transport models of the intestinal epithelium. More recently, human enterocyte cell culture models (such as Caco-2 cells) were coupled with simulated GI models. Small intestinal digestive processes or following further colonic fermentation have been widely used as a predictive tool for the absorption of bioactive components from foods (Chitchumroonchokchai and Failla 2006; Failla and others 2008a; Biehler and others 2010). Caco-2 is a cell line which originated from a human colon carcinoma, exhibiting some morphological and functional characteristics similar to those of differentiated epithelial cells of the intestinal mucosa (Sambruy and others 2001). The in vitro digestion/Caco-2 cell culture model developed by Glahn and others (1998) has been validated and offers a rapid, low-cost method for screening foods and food combinations for iron uptake before more definitive human trials (Hur and others 2011). Caco-2 cells have also been applied to a number of uptake and transport studies for both hydrophilic constituents (such as polyphenols) and lipophilic compounds (such as carotenoids). The behavior of carotenoids from the in vitro digestion/Caco2 cell culture model has been well correlated, qualitatively and quantitatively, with human data (Garrett and others 1999, 2000; Mahler and others 2009). While the majority of studies have focused on simple uptake employing a biphasic model with the apical membrane and the cell layer, transport models including also an additional basolateral compartment are also available to allow the study of fluxes and, therefore, kinetic parameters through the cell layer (Reboul and others 2006; Biehler and others 2010; Manzano and Williamson 2010). However, the latter requires transwell inserts, which are more costly, and the concentrations to be determined are usually lower and may require more sophisticated analytical techniques for detection, such as mass spectrometry, and it may not be feasible to study minor food constituents. More recently, the Caco-2 cell model has been extended by adding a layer of mucus-producing cells (such as HT-29 MTX cells) on top of the Caco-2 cells. However, only preliminary data are available on how this system performs compared to Caco-2 cells alone, although this may represent a more realistic approach, which may further hamper uptake of more lipophilic constituents due to the additional mechanical barrier (Nollevaux and others 2006). Also, Ussing chambers have been used to obtain a better understanding of the transepithelial transport processes on a molecular basis. This is a model that simulates the mucosa and its luminal/apical side (Bergmann and others 2009; Clarke 2009). For example, Deusser and others (2013) have used the Ussing chamber to evaluate apple polyphenol transport and their effect on mucosal integrity.

\section{Conclusions and Summary}

Many considerations have to be taken into account when determining bioaccessibility of phytochemicals by means of in vitro digestion models. Two important criteria are whether the focus of research is on hypothesis building and a large number of samples is to be analyzed, which favor static models, or if closely simulating physiological conditions is the primary aim, which favors the use of dynamic models. An additional criterion is the lipophilicity of the phytochemicals of interest. For hydrophilic compounds such as for polyphenols, often associated with fiber or complex carbohydrates, amylase digestion and perhaps particle size appear to play predominant roles. Whereas, for lipophilic compounds, (such as carotenoids) emulsifying agents (presence of dietary fats, bile salts, and sufficient lipolytic activity), appear crucial, thus their use during digestion should be well considered and standardized. This also includes adjusting $\mathrm{pH}$ values and allowing sufficient digestion times for optimal enzyme function comparable to the in vivo situation. The suggested conditions for static digestion models are outlined in Table 5. These parameters represent a consensus from commonly employed conditions for simulated static in vitro digestion (Table 1 to 4), but also take into account practical aspects (such as availability of enzymes) but, most importantly, are also similar to the in vivo situation. In addition, lipophilic phytochemicals require separation of the micellar fraction prior to further investigations, via ultracentrifugation (static model), filtration, or employing a membrane (dynamic model). Coupling the cell-based 
uptake model with colonic digestion models is a comparatively novel but important completion of modeling digestion. This may especially be suitable for compounds such as polyphenols, which are metabolized and taken up from the colon.

Untilnow, the lack of consensus values for the digestion parameters has hampered possibilities to compare results across different studies. Though the suggested conditions are based on relevant in vivo data, further studies are required to validate their use and limitations in phytochemicals digestion. Mindful of their limitations, much insightful information has been gained from applying in vitro digestion models to phytochemical research. The recent improvements in our understanding and the advances in the technology warrant continuous research in the important area of bioavailability.

\section{Acknowledgments}

The authors thank André Brodkorb, for his critical reading of the manuscript and helpful suggestions, and Grethe Iren Borge, for her recommendations. Also, the COST action FA1005 Infogest is acknowledged for providing funding for travel and meetings. The authors also acknowledge support from Fundação para a Ciência e a Tecnologia under grants PEstOE/EQB/LA0004/2011 and SRFH/BPD/84618/2012 (CNS), to the Scottish Government Strategic Research and Partnership Programmes (GJM), to the European Commission for financial support of EUBerry FP7 KBBE2010-4 265942 (CNS), EtherPaths FP7-KBBE-222639 (AMA), and to the Spanish MINECO (Grants: AGL2009-13361-C02-02, AGL2012-35814, RM2011-00003-00-00 and Consolider Ingenio 2010 FUN-C-FOOD-CSD2007-00063) (TR).

\section{Conflicts of Interest}

The authors report no conflicts of interest. The authors alone are responsible for the content and writing of the paper.

\section{References}

Adlercreutz H, van der Wildt J, Kinzel J, Attalla H, Wahala K, Makela T,

Hase T, Fotsis T. 1995. Lignan and isoflavonoid conjugates in human urine. J Steroid Biochem Mol Biol 52:97-103.

Aherne SA, Daly T, Jiwan MA, O’Sullivan L, O'Brien NM. 2010.

Bioavailability of $\beta$-carotene isomers from raw and cooked carrots using an in vitro digestion model coupled with a human intestinal Caco-2 cell model. Food Res Intl 43:1449-54.

Aps JKM, Martens LC. 2005. Review: the physiology of saliva and transfer of drugs into saliva. Forensic Sci Intl 150:119-31.

Armand M. 2007. Lipases and lipolysis in the human digestive tract: where do we stand? Curr Opin Clin Nutr Metab Care 10:156-64.

Armand M, Borel P, Dubois C, Senft M, Peyrot J, Salducci J, Lafont H, Lairon D. 1994. Characterization of emulsions and lipolysis of dietary lipids in the human stomach. Am J Physiol 266:G372-81.

Armand M, Hamosh M, DiPalma JS, Gallagher J, Benjamin SB, Philpott JR, Lairon D, Hamosh P. 1995. Dietary fat modulates gastric lipase activity in healthy humans. Am J Clin Nutr 62:74-80.

Armand M, Borel P, Pasquier B, Dubois C, Senft M, Andre M, Peyrot J, Salducci J, Lairon D. 1996a. Physicochemical characteristics of emulsions during fat digestion in human stomach and duodenum. Am J Physiol 271:G172-83.

Armand M, Hamosh M, Mehta NR, Angelus PA, Philpott JR, Henderson TR, Dwyer NK, Lairon D, Hamosh P. 1996b. Effect of human milk or formula on gastric function and fat digestion in the premature infant. Pediatr Res 40:429-37.

Armand M, Pasquier B, André M, Borel P, Senft M, Peyrot J, Salducci J, Portugal H, Jaussan V, Lairon D. 1999. Digestion and absorption of 2 fat emulsions with different droplet sizes in the human digestive tract. Am J Clin Nutr 70(6):1096-106.
Arranz S, Manuel Silvan J, Saura-Calixto F. 2010. Nonextractable polyphenols, usually ignored, are the major part of dietary polyphenols: a study on the Spanish diet. Mol Nutr Food Res 54:1646-58.

Arts ICW, Hollman PCH. 2005. Polyphenols and disease risk in epidemiologic studies. Am J Clin Nutr 81:317S-25S.

Arumugam M, Raes J, Pelletier E, Le Paslier D, Yamada T, Mende DR, Fernandes GR, Tap J, Bruls T, Batto JM, Bertalan M, Borruel N, Casellas F, Fernandez L, Gautier L, Hansen T, Hattori M, Hayashi T, Kleerebezem M, Kurokawa K, Leclerc M, Levenez F, Manichanh C, Nielsen HB, Nielsen T, Pons N, Poulain J, Qin J, Sicheritz-Ponten T, Tims S, Torrents D, Ugarte E, Zoetendal EG, Wang J, Guarner F, Pedersen O, de Vos WM, Brunak S, Doré J; MetaHIT Consortium, Antolín M, Artiguenave F, Blottiere HM, Almeida M, Brechot C, Cara C, Chervaux C, Cultrone A, Delorme C, Denariaz G, Dervyn R, Foerstner KU, Friss C, van de Guchte M, Guedon E, Haimet F, Huber W, van Hylckama-Vlieg J, Jamet A, Juste C, Kaci G, Knol J, Lakhdari O, Layec S, Le Roux K, Maguin E, Mérieux A, Melo Minardi R, M'rini C, Muller J, Oozeer R, Parkhill J, Renault P, Rescigno M, Sanchez N, Sunagawa S, Torrejon A, Turner K, Vandemeulebrouck G, Varela E, Winogradsky Y, Zeller G, Weissenbach J, Ehrlich SD, Bork P. 2011. Enterotypes of the human gut microbiome. Nature 473:174-80.

Aura A-M., Martin-Lopez P, O’Leary KA, Williamson G,

Oksman-Caldentey K-M, Poutanen K, Santos-Buelga C. 2005. In vitro metabolism of anthocyanins by human gut microbiota. Eur J Nutr 44:133-42.

Aura A-M. 2008. Microbial metabolism of dietary phenolic compounds in the colon. Phytochem Rev 7:407-29.

Aura A-M, O’Leary KA, Williamson G, Ojala M, Bailey M,

Puupponen-Pimiä R, Nuutila AM, Oksman-Caldentey KM, Poutanen K. 2002. Quercetin derivatives are deconjugated and converted to hydroxyphenylacetic acids but not methylated by human fecal flora in vitro. J Agric Food Chem 50:1725-30.

Aura A-M, Mattila I, Seppänen-Laakso T, Miettinen J, Oksman-Caldentey K-M, Orešič M. 2008. Microbial metabolism of catechin stereoisomers by human faecal microbiota: Comparison of targeted analysis and a non-targeted metabolomics method. Phytochem Lett 1:18-22.

Aura A-M, Mattila I, Hyötyläinen T, Gopalacharyulu P, Cheynier V, Souquet J-M, Bes M, Bourvellec C, Guyot S, Orešič M. 2012. Characterization of microbial metabolism of Syrah grape products in an in vitro colon model using targeted and non-targeted analytical approaches. Eur J Nutr 52:833-46.

Ballance S, Sahlstrøm S, Lea P, Nagy N, Andersen P, Dessev T, Hull S, Vardakou M, Faulks R. 2013. Evaluation of gastric processing and duodenal digestion of starch in six cereal meals on the associated glycaemic response using an adult fasted dynamic gastric model. Eur J Nutr 52:799-812.

Barrington R, Williamson G, Bennett RN, Davis BD, Brodbelt JS, Kroon PA. 2009. Absorption, conjugation and efflux of the flavonoids, kaempferol and galangin, using the intestinal $\mathrm{CaCo}-2 / \mathrm{TC} 7$ cell model. J Funct Foods 1(1):74-87.

Barry JL, Hoebler C, Macfarlane GT, Macfarlane S, Methers JC, Reed KA, Mortensen PB, Norgarrds I, Rowland IR, Rumney CJ. 1995. Estimation of the fermentability of dietary fibre in vitro: a European interlaboratory study. Br J Nutr 74:303-22.

Bassinello PZ, Cordenunsi BR, Lajolo FM. 2002. Amylolytic activity in fruits: a comparison of different substrates and methods using banana as model. J Agric Food Chem 50:5781-6.

Beer MU, Wood PJ, Weisz J, Fillion N. 1997. Effect of cooking and storage on the amount and molecular weight of $(1 \rightarrow 3)(1 \rightarrow 4)-\beta$-d-glucan extracted from oat products by an in vitro digestion system. Cereal Chem 74:705-9.

Bengtsson A, Larsson Alminger M, Svanberg U. 2009. In vitro bioaccessibility of $\beta$-carotene from heat-processed orange-fleshed sweet potato. J Agric Food Chem 57:9693-8.

Bengtsson A, Brackmann C, Enejder A, Alminger ML, Svanberg U. 2010. Effects of thermal processing on the in vitro bioaccessibility and microstructure of $\beta$-carotene in orange-fleshed sweet potato. J Agric Food Chem 58:11090-6.

Bennick A. 2002. Interaction of plant polyphenols with salivary proteins. Crit Rev Oral Biol Med 13:184-96.

Bergmann H, Rogoll D, Scheppach W, Melcher R, Richling E. 2009. The Ussing type chamber model to study the intestinal transport and modulation of specific tight-junction genes using a colonic cell line. Mol Nutr Food Res 53(10):1211-25.

Bermudez-Soto MJ, Tomas-Barberan FA, Garcia-Conesa MT. 2007. Stability of polyphenols in chokeberry (Aronia melanocarpa) subjected to in vitro gastric and pancreatic digestion. Food Chem 102:86574. 
Biehler E, Bohn T. 2010. Methods for assessing aspects of carotenoid bioavailability. Curr Nutr Food Sci 6:44-69.

Biehler E, Kaulmann A, Hoffmann L, Krause E, Bohn T. 2011a. Dietary and host-related factors influencing carotenoid bioaccessibility from spinach (Spinacia oleracea). Food Chem 125:1328-34.

Biehler E, Hoffmann L, Krause E, Bohn T. 2011b. Divalent minerals decrease micellarization and uptake of carotenoids and digestion products into Caco-2 cells. J Nutr 141:1769-76.

Blanquet-Diot S, Soufi M, Rambeau M, Rock E, Alric M. 2009. Digestive stability of xanthophylls exceeds that of carotenes as studied in a dynamic in vitro gastrointestinal system. J Nutr 139:876-83.

Bohin MC, Vincken JP, van der Hijden H, Gruppen H. 2012. Efficacy of food proteins as carriers for flavonoids. J Agric Food Chem 60: 4136-43.

Bohn T. 2008. Bioavailability of non-provitamin A carotenoids. Curr Nutr Food Sci 4:240-58.

Bohn T, Tian Q, Schwartz SJ, Failla ML. 2007. Fat-free phytosterol products supplemented to test meals can reduce cholesterol micellarization and inhibit cholesterol accumulation by Caco- 2 cells as determined enzymatically and by stable isotope techniques. J Food Sci Agric 55:267-72. Boileau AC, Merchen NR, Wasson K, Atkinson CA, Erdman Jr JW. 1999. Cis-lycopene is more bioavailable than trans-lycopene in vitro and in vivo in lymph-cannulated ferrets. J Nutr 129:1176-81.

Bolca S, Wyns C, Possemiers S, Depypere H, De Keukeleire D, Bracke M, Verstraete W, Heyerick A. 2009. Cosupplementation of isoflavones, prenylflavonoids, and lignans alters human exposure to phytoestrogen-derived $17 \beta$-estradiol equivalents. J Nutr 139:2293-300.

Bolca S, Van de Wiele T, Possemiers S. 2012. Gut metabotypes govern health effects of dietary polyphenols. Curr Opin Biotechnol 24:220-5.

Borgstrom B, Dahlqvist A, Lundh G, Sjovall J. 1957. Studies of intestinal digestion and absorption in the human. J Clin Invest 36:1521-36.

Bouayed J, Hoffmann L, Bohn T. 2011. Total phenolics, flavonoids, anthocyanins and antioxidant activity following simulated gastro-intestinal digestion and dialysis of apple varieties: bioaccessibility and potential uptake. Food Chem 128:14-21.

Bouayed J, Deußer H, Hoffmann L, Bohn T. 2012. Bioaccessible and dialysable polyphenols in selected apple varieties following in vitro digestion vs. their native patterns. Food Chem 131:1466-72.

Braganza JM, Herman K, Hine P, Kay G, Sandle GI. 1978. Pancreatic enzymes in human duodenal juice- a comparison of responses in secretin pancreozymin and Lundh Borgstrom tests. Gut 19:358-66.

Braune A, Bunzel M, Yonekura R, Blaut M. 2009. Conversion of dehydrodiferulic acids by human intestinal microbiota. J Agric Food Chem 57:3356-62.

Brouillard R, Wigand MC, Dangles O, Cheminat A. 1991. pH and solvent effects on the copigmentation reaction of malvin with polyphenols, purine and pyrimidine derivatives. J Chem Soc 2:1235-41.

Brown EM, McDougall GJ, Stewart D, Pereira-Caro G, González-Barrio R, Allsopp P, Magee P, Crozier A, Rowland I, Gill CIR. 2012. Persistence of anticancer activity in berry extracts after simulated gastrointestinal digestion and colonic fermentation. PLoS ONE 7:e49740.

Brunner G, Hell M, Hengels KJ, Hennig U, Fuchs W. 1995. Influence of lansoprazole on intragastric 24-hour $\mathrm{pH}$, meal-stimulated gastric acid secretion, and concentrations of gastrointestinal hormones and enzymes in serum and gastric juice in healthy volunteers. Digestion 56:137-44.

Capolino P, Guérin C, Paume J, Giallo J, Ballester J-M, Cavalier J-F, Carrière F. 2011. In vitro gastrointestinal lipolysis: replacement of human digestive lipases by a combination of rabbit gastric and porcine pancreatic extracts. Food Dig 2:43-51.

Carriere F, Barrowman JA, Verger R, Laugier R. 1993. Secretion and contribution to lipolysis of gastric and pancreatic lipases during a test meal in humans. Gastroenterology 105:876-88.

Carter P, Gray LJ, Troughton J, Khunti K, Davies MJ. 2010. Fruit and vegetable intake and incidence of type 2 diabetes mellitus: systematic review and meta-analysis. BMJ 341:c4229.

Cerda B, Espin JC, Parra S, Martinez P, Tomás-Barberán FA. 2004. The potent in vitro antioxidant ellagitannins from pomegranate juice are metabolised into bioavailable but poor antioxidant

hydroxy-6H-dibenzopyran-6-one derivatives by the colonic microflora of healthy humans. Eur J Nutr 43:205-20.

Chen J, Gaikwad V, Holmes M, Murray B, Povey M, Wang Y, Zhang Y. 2011. Development of a simple model device for in vitro gastric digestion investigation. Food Funct 2:174-82.
Chitchumroonchokchai C, Failla ML. 2006. Hydrolysis of zeaxanthin esters by carboxyl ester lipase during digestion facilitates micellarization and uptake of the xanthophyll by Caco-2 human intestinal cells. J Nutr 136:588-94.

Chitchumroonchokchai C, Schwartz SJ, Failla ML. 2004. Assessment of lutein bioavailability from meals and a supplement using simulated digestion and Caco-2 human intestinal cells. J Nutr 134:2280-86.

Cilla A, González-Sarrías A, Tomás-Barberán FA, Espín JC, Barberá R. 2009. Availability of polyphenols in fruit beverages subjected to in vitro gastrointestinal digestion and their effects on proliferation, cell-cycle and apoptosis in human colon cancer Caco-2 cells. Food Chem 114:813-20.

Cilla A, Perales S, Lagarda MJ, Barberá R, Clemente G, Farré R. 2011. Influence of storage and in vitro gastrointestinal digestion on total antioxidant capacity of fruit beverages. J Food Compost Anal 24:87-94.

Clarke LL. 2009. A guide to Ussing chamber studies of mouse intestine. Am J Physiol Gastrointest Liver Physiol 296(6):G1151-66

Clarysse S, Tack J, Lammert F, Duchateau G, Reppas C, Augustijns P. 2009. Postprandial evolution in composition and characteristics of human duodenal fluids in different nutritional states. J Pharm Sci 98:1177-92.

Clifford MN. 2000. Anthocyanins-nature, occurence and dietary burden. J Sci Food Agric 80:1063-72.

Clifford MN, Scalbert A. 2000. Ellagitannins-nature, occurrence and dietary burden. J Sci Food Agric 80:1118-25.

Colle I, Van Buggenhout S, Van Loey A, Hendrickx M. 2010. High-pressure homogenization followed by thermal processing of tomato pulp: influence on microstructure and lycopene in vitro bioaccessibility. Food Res Intl 43:2193-200.

Courraud J, Berger J, Cristol J-P, Avallone S. 2013. Stability and bioaccessibility of different forms of carotenoids and vitamin A during in vitro digestion. Food Chem 136:871-77.

Czank C, Cassidy A, Zhang Q, Morrison DJ, Preston T, Kroon PA, Botting NP, Kay CD. 2013. Human metabolism and elimination of the anthocyanin, cyanidin-3-glucoside: a (13)C-tracer study. Am J Clin Nutr 97(5):995-1003.

Dangles O, Dufour C. 2005. Flavonoid-protein interactions. In: Andersen $\varnothing \mathrm{M}$, Markham KR, editors. Flavonoids: chemistry, biochemistry and applications. Boca Raton, Fla.: CRC Press. p 443-464.

Dangles O, Dufour C. 2008. Flavonoid-protein binding processes and their potential impact on human health. In: Daayf F, Lattanzio V, editors. Recent Advances in Polyphenol Research, Volume 1. Wiley-Blackwell, Oxford, UK.

Daniel EM, Ratnayake S, Kinstle T, Stoner GD. 1991. The effects of $\mathrm{pH}$ and rat intestinal contents on the liberation of ellagic acid from purified and crude ellagitannins. J Nat Prod 54:946-52.

Darwiche G, Almer LO, Bjorgell O, Cederholm C, Nilsson P. 1999. Measurement of gastric emptying by standardized real-time ultrasonography in healthy subjects and diabetic patients. J Ultrasound Med 18:673-82.

Daugherty AL, Mrsny RJ. 1999. Transcellular uptake mechanisms of the intestinal epithelial barrier. Part one. Pharm Sci Technolo Today 2:144-51.

Day AJ, Cañada FJ, Díaz JC, Kroon PA, McLauchlan R, Faulds CB, Plumb GW, Morgan MRA, Williamson G. 2000. Dietary flavonoid and isoflavone glycosides are hydrolysed by the lactase site of lactase phlorizin hydrolase. FEBS Lett 468:166-70.

Daykin CA, Van Duynhoven JP, Groenewegen A, Dachtler M, Van Amelsvoort JM, Mulder TP. 2005. Nuclear magnetic resonance spectroscopic based studies of the metabolism of black tea polyphenols in humans. J Agric Food Chem 53:1428-34.

de Freitas V, Mateus N. 2001. Structural features of procyanidin interactions with salivary proteins. J Agric Food Chem 49:940-5.

de Pascual-Teresa S, Hallund J, Talbot D, Schroot J, Williams CM, Bugel S, Cassidy A. 2006. Absorption of isoflavones in humans: effects of food matrix and processing. J Nutr Biochem 17:257-64.

Déat E, Blanquet-Diot SP, Jarrige J-Fo, Denis S, Beyssac E, Alric M. 2009. Combining the dynamic TNO-gastrointestinal tract system with a Caco-2 cell culture model: application to the assessment of lycopene and $\alpha$-tocopherol bioavailability from a whole food. J Agric Food Chem 57:11314-20.

Degen LP, Phillips SF. 1996. Variability of gastrointestinal transit in healthy women and men. Gut 39:299-305.

Deusser H, Rogoll D, Scheppach W, Volk A, Melcher R, Richling E. 2013. Gastrointestinal absorption and metabolism of apple polyphenols ex vivo by the pig intestinal mucosa in the Ussing chamber. Biotechnol J $8(3): 363-70$. 
Dhuique-Mayer C, Borel P, Reboul E, Caporiccio B, Besancon P, Amiot MJ. 2007. Beta-cryptoxanthin from citrus juices: assessment of bioaccessibility using an in vitro digestion/Caco-2 cell culture model. $\mathrm{Br} \mathrm{J}$ Nutr 97:883-90.

Dukehart MR, Dutta SK, Vaeth J. 1989. Dietary fiber supplementation: effect on exocrine pancreatic secretion in man. Am J Clin Nutr 50:1023-8.

Dupas C, Baglieri AM, Ordonaud C, Tome D, Maillard MN. 2006. Chlorogenic acid is poorly absorbed, independently of the food matrix: a Caco- 2 cells and rat chronic absorption study. Mol Nutr Food Res 50:1053-60.

Eastwood M, Morris E. 1992. Physical properties of dietary fiber that influence physiological function: a model for polymers along the gastrointestinal tract. Am J Clin Nutr 55:436-42.

Ellis PR, Kendall CW, Ren Y, Parker C, Pacy JF, Waldron KW, Jenkins DJ. 2004. Role of cell walls in the bioaccessibility of lipids in almond seeds. Am J Clin Nutr 80:604-13.

Engelen L, de Wijk RA, Prinz JF, van der Bilt A, Bosman F. 2003. The relation between saliva flow after different stimulations and the perception of flavor and texture attributes in custard desserts. Physiol Behav 78:165-9.

Erk T, Williamson G, Renouf M, Marmet C, Steiling H, Dionisi F, Barron D, Melcher R, Richling E. 2012. Dose-dependent absorption of chlorogenic acids in the small intestine assessed by coffee consumption in ileostomists. Mol Nutr Food Res 56:1488-500.

Etcheverry P, Grusak MA, Fleige LE. 2012. Application of in vitro bioaccessibility and bioavailability methods for calcium, carotenoids, folate, iron, magnesium, polyphenols, zinc and vitamins B6, B12, D, and E. Front Physiol 3:317.

Failla ML, Chitchumroonchokchai C, Ishida BK. 2008a. In vitro micellarization and intestinal cell uptake of cis isomers of lycopene exceed those of all-trans lycopene. J Nutr 138:482-6.

Failla ML, Huo T, Thakkar SK. 2008b. In vitro screening of relative bioaccessibility of carotenoids from foods. Asia Pac J Clin Nutr 17:200-3.

Failla ML, Thakkar SK, Kim JY. 2009. In vitro bioaccessibility of $\beta$-carotene in orange fleshed sweet potato (Ipomoea batatas, Lam.). J Agric Food Chem 57:10922-27.

Faulks RM, Hart DJ, Scott KJ, Southon S. 1998. Changes in plasma carotenoid and vitamin E profile during supplementation with oil palm fruit carotenoids. J Lab Clin Med 132:507-11.

Fazzari M, Fukumoto L, Mazza G, Livrea MA, Tesoriere L, Di Marco L. 2008. In vitro bioavailability of phenolic compounds from five cultivars of frozen sweet cherries (Prunus avium L.). J Agric Food Chem 56:356168.

Feldman M, Cryer B, Lee E. 1998. Effects of Helicobacter pylori gastritis on gastric secretion in healthy human beings. Am J Physiol 274:G1011-7.

Fleschhut J, Kratzer F, Rechkemmer G, Kulling SE. 2006. Stability and biotransformation of various dietary anthocyanins in vitro. Eur J Nutr 45:7-18.

Fogliano V, Corollaro ML, Vitaglione P, Napolitano A, Ferracane R, Travaglia F, Arlorio M, Costabile A, Klinder A, Gibson G. 2011. In vitro bioaccessibility and gut biotransformation of polyphenols present in the water-insoluble cocoa fraction. Mol Nutr Food Res 55:S44-55.

Gao K, Xu AL, Krul C, Venema K, Liu Y, Niu YT, Lu JX, Bensoussan L, Seeram NP, Heber D, Henning SM. 2006. Of the major phenolic acids formed during human microbial fermentation of tea, citrus, and soy flavonoid supplements, only 3,4-dihydroxyphenylacetic acid has antiproliferative activity. J Nutr 136:52-7.

Gardner JD, Ciociola AA, Robinson M. 2002. Measurement of meal-stimulated gastric acid secretion by in vivo gastric autotitration. J Appl
Physiol 92:427-34.

Garidel P, Hildebrand A, Knauf K, Blume A. 2007. Membranolytic activity of bile salts: influence of biological membrane properties and composition. Molecules 12:2292-326.

Garrett DA, Failla ML, Sarama RJ. 1999. Development of an in vitro digestion method to assess carotenoid bioavailability from meals. J Agric Food Chem 47:4301-9.

Garrett DA, Failla ML, Sarama RJ. 2000. Estimation of carotenoid bioavailability from fresh stir-fried vegetables using an in vitro digestion/Caco-2 cell culture model. J Nutr Biochem 11:574-80.

Gartner C, Stahl W, Sies H. 1997. Lycopene is more bioavailable from tomato paste than from fresh tomatoes. Am J Clin Nutr 66:116-22.

Gawlik-Dziki U. 2012. Changes in the antioxidant activities of vegetables as a consequence of interactions between active compounds. J Funct Foods $4: 872-82$.
Gawlik-Dziki U, Dziki D, Baraniak B, Lin R. 2009. The effect of simulated digestion in vitro on bioactivity of wheat bread with Tartary buckwheat flavones addition. LWT - Food Sci Technol 42:137-43.

Gil-Izquierdo A, Zafrilla P, Tomas-Barberan FA. 2002. An in vitro method to simulate phenolic compound release from the food matrix in the gastrointestinal tract. Eur Food Res Technol 214:155-9.

Gil-Izquierdo A, Gil MI, Tomás-Barberán FA, Ferreres F. 2003. Influence of industrial processing on orange juice flavanone solubility and transformation to chalcones under gastrointestinal conditions. J Agric Food Chem 51:3024-28.

Ginsburg I, Koren E, Shalish M, Kanner J, Kohen R. 2012. Saliva increases the availability of lipophilic polyphenols as antioxidants and enhances their retention in the oral cavity. Arch Oral Biol 57:1327-34.

Glahn RP, Lee OA, Yeung A, Goldman MI, Miller DD. 1998. Caco-2 cell ferritin formation predicts nonradiolabeled food iron availability in an in vitro digestion/Caco-2 cell culture model. J Nutr 128:1555-61.

Goetze O, Steingoetter A, Menne D, van der Voort IR, Kwiatek MA,

Boesiger P, Weishaupt D, Thumshirn M, Fried M, Schwizer W. 2007. The effect of macronutrients on gastric volume responses and gastric emptying in humans: a magnetic resonance imaging study. Am J Physiol Gastrointest Liver Physiol 292(1):G11-7.

Golding M, Wooster TJ. 2010. The influence of emulsion structure and stability on lipid digestion. Curr Opin Colloid Interface Sci 15:90-101.

Gonçalves R, Soares S, Mateus N, De Freitas V. 2007. Inhibition of trypsin by condensed tannins and wine. J Agric Food Chem 55(18):7596-601.

González-Barrio R, Edwards CA, Crozier A. 2011. Colonic catabolism of ellagitannins, ellagic acid, and raspberry anthocyanins: in vivo and in vitro studies. Drug Metab Dispos 39:1680-8.

Gorelik S, Lapidot T, Shaham I, Granit R, Ligumsky M, Kohen R, Kanner J. 2005. Lipid peroxidation and coupled vitamin oxidation in simulated and human gastric fluid inhibited by dietary polyphenols: health implications. J Agric Food Chem 53:3397-402.

Gorelik S, Ligumsky M, Kohen R, Kanner J. 2008. A novel function of red wine polyphenols in humans: prevention of absorption of cytotoxic lipid peroxidation products. Faseb J 22:41-6.

Granado-Lorencio F, Olmedilla-Alonso B, Herrero-Barbudo C,

Blanco-Navarro I, Pérez-Sacristán B, Blázquez-García S. 2007. In vitro bioaccessibility of carotenoids and tocopherols from fruits and vegetables. Food Chem 102:641-48.

Green RJ, Murphy AS, Schulz B, Watkins BA, Ferruzzi MG. 2007. Common tea formulations modulate in vitro digestive recovery of green tea catechins. Mol Nutr Food Res 51:1152-62.

Gross M, Pfeiffer M, Martini M, Campbell D, Slavin J, Potter J. 1996. The quantitation of metabolites of quercetin flavonols in human urine. Cancer Epidemiol Biomarkers Prev 5:711-20.

Gross G, Jacobs DM, Peters S, Possemiers S, van Duynhoven J, Vaughan EE, van de Wiele T. 2010. In vitro bioconversion of polyphenols from black tea and red wine/grape juice by human intestinal microbiota displays strong interindividual variability. J Agric Food Chem 58:10236-46.

Guerra A, Etienne-Mesmin L, Livrelli V, Denis S, Blanquet-Diot S, Alric M. 2012. Relevance and challenges in modeling human gastric and small intestinal digestion. Trends Biotechnol 30:591-600.

Gumienna M, Lasik M, Czarnecki Z. 2011. Bioconversion of grape and chokeberry wine polyphenols during simulated gastrointestinal in vitro digestion. Intl J Food Sci Nutr 62:226-33.

Guyton AC, Hall JE. 1996. Digestion and absorption in the gastrointestinal tract. In: Textbook of medical physiology. 9th ed. Philadelphia: W.B. Saunders Co. p 833-44.

Hamer M, Chida Y. 2007. Intake of fruit, vegetables, and antioxidants and risk of type 2 diabetes: systematic review and meta-analysis. J Hypertens 25:2361-9.

Haratifar S, Corredig M. 2014. Interactions between tea catechins and casein micelles and their impact on renneting functionality. Food Chem 143:27-32.

He GL, Shankar RA, Chzhan M, Samouilov A, Kuppusamy P, Zweier JL. 1999. Noninvasive measurement of anatomic structure and intraluminal oxygenation in the gastrointestinal tract of living mice with spatial and spectral EPR imaging. PNAS 96:4586-91.

He Q, Lv Y, Yao K. 2006. Effects of tea polyphenols on the activities of alpha-amylase, pepsin, trypsin and lipase. Food Chem 101(3):1178-82.

He FJ, Nowson CA, Lucas M, MacGregor GA. 2007. Increased consumption of fruit and vegetables is related to a reduced risk of coronary heart disease: meta-analysis of cohort studies. J Hum Hypertens 21:717-28. 
Hedrén E, Mulokozi G, Svanberg U. 2002. In vitro accessibility of carotenes from green leafy vegetables cooked with sunflower oil or red palm oil. Intl J Food Sci Nutr 53:445-53.

Heinonen S, Nurmi T, Liukkonen K, Poutanen K, Wahala K, Deyama T, Nishibe S, Adlercreutz H. 2001. In vitro metabolism of plant lignans: new precursors of mammalian lignans enterolactone and enterodiol. J Agric Food Chem 49:3178-86.

Hemery YM, Anson NM, Havenaar R, Haenen GRMM, Noort MWJ, Rouau X. 2010. Dry-fractionation of wheat bran increases the bioaccessibility of phenolic acids in breads made from processed bran fractions. Food Res Intl 43:1429-38.

Hoebler C, Karinthi A, Devaux MF, Guillon F, Gallant DJ, Bouchet B, Melegari C, Barry JL. 1998. Physical and chemical transformations of cereal food during oral digestion in human subjects. Br J Nutr 80:429-36.

Hoebler C, Devaux MF, Karinthi A, Belleville C, Barry JL. 2000. Particle size of solid food after human mastication and in vitro simulation of oral breakdown. Intl J Food Sci Nutr 51:353-66.

Holmes R, Lobley RW. 1989. Intestinal brush border revisited. Gut 30(12):1667-78

Huo T, Ferruzzi MG, Schwartz SJ, Failla ML. 2007. Impact of fatty acyl composition and quantity of triglycerides on bioaccessibility of dietary carotenoids. J Agric Food Chem 55:8950-57.

Hur SJ, Lim BO, Decker EA, McClements DJ. 2011. In vitro human digestion models for food applications. Food Chem 125:1-12.

Iori R, Barillari J, Rollin P. 2004. Comment on in vitro gastrointestinal digestion study of broccoli inflorescence phenolic compounds, glucosinolates, and vitamin C. J Agric Food Chem 52(24):7432-3.

Isenman L, Liebow C, Rothman S. 1999. The endocrine secretion of mammalian digestive enzymes by exocrine glands. Am J Physiol 276:E223-32.

Jacobs DM, Fuhrmann JC, van Dorsten FA, Rein D, Peters S, van Velzen EJ Hollebrands B, Draijer R, van Duynhoven J, Garczarek U. 2012. Impact of short-term intake of red wine and grape polyphenol extract on the human metabolome. J Agric Food Chem 60:3078-85.

Jakob M. 2008. Normalwerte pocket. 5th ed. Grunwald: Börm Bruckmeier Verlag.

Joannou GE, Kelly GE, Reeder AY, Waring M, Nelson C. 1995. A urinary profile study of dietary phytoestrogens. The identification and mode of metabolism of new isoflavonoids. J Steroid Biochem Mol Biol 54:167-84.

Johnsen NF, Hausner H, Olsen A, Tetens I, Christensen J, Knudsen KE, Overvad K, Tjonneland A. 2004. Intake of whole grains and vegetables determines the plasma enterolactone concentration of Danish women. J Nutr 134:2691-7.

Kahle K, Kempf M, Schreier P, Scheppach W, Schrenk D, Kautenburger T, Hecker D, Huemmer W, Ackermann M, Richling E. 2011. Intestinal transit and systemic metabolism of apple polyphenols. Eur J Nutr 50(7):507-22.

Kalantzi L, Goumas K, Kalioras V, Abrahamsson B, Dressman JB, Reppas C. 2006. Characterization of the human upper gastrointestinal contents under conditions simulating bioavailability/bioequivalence studies. Pharm Res 23:165-76.

Karakaya S. 2004. Bioavailability of phenolic compounds. Crit Rev Food Sci Nutr 44:453-64.

Karakaya S, Yilmaz N. 2007. Lycopene content and antioxidant activity of fresh and processed tomatoes and in vitro bioavailability of lycopene. J Sci Food Agric 87:2342-7.

Kern SM, Bennett RN, Mellon FA, Kroon PA, Garcia-Conesa MT. 2003. Absorption of hydroxycinnamates in humans after high-bran cereal consumption. J Agric Food Chem 51:6050-5.

Kiers JL, Nout RMJ, Rombouts FM. 2000. In vitro digestibility of processed and fermented soya bean, cowpea and maize. J Sci Food Agric 80:1325-31.

Kilkkinen A, Stumpf K, Pietinen P, Valsta LM, Tapanainen H, Adlercreutz H. 2001. Determinants of serum enterolactone concentration. Am J Clin Nutr 73:1094-100

Kim SK. 1968. Small intestine transit time in the normal small bowel study Am J Roentgenol Radium Ther Nucl Med 104:522-4.

Knaup B, Kahle K, Erk T, Valotis A, Scheppach W, Schreier P, Richling E. 2007. Human intestinal hydrolysis of phenol glycosides—a study with quercetin and p-nitrophenol glycosides using ileostomy fluid. Mol Nutr Food Res 51(11):1423-9.

Kong F, Singh RP. 2010. A human gastric simulator (HGS) to study food digestion in human stomach. J Food Sci 75:E627-35.
Kopf-Bolanz KA, Schwander F, Gijs M, Vergeres G, Portmann R, Egger L. 2012. Validation of an in vitro digestive system for studying macronutrient decomposition in humans. J Nutr 142:245-50.

Krzyzanowska J, Czubacka A, Oleszek W. 2010. Dietary phytochemicals and human health. Adv Exp Med Biol 698:74-98.

Kuijsten A, Arts IC, Vree TB, Hollman PC. 2005. Pharmacokinetics of enterolignans in healthy men and women consuming a single dose of secoisolariciresinol diglucoside. J Nutr 135:795-801.

Kuijsten A, Arts IC, Hollman PC, van't Veer P, Kampman E. 2006. Plasma enterolignans are associated with lower colorectal adenoma risk. Cancer Epidemiol Biomarkers Prev 15:1132-6.

Kulp KS, Fortson SL, Knize MG, Felton JS. 2003. An in vitro model system to predict the bioaccessibility of heterocyclic amines from a cooked meat matrix. Food Chem Toxicol 41:1701-10.

Kwiatek MA, Menne D, Steingoetter A, Goetze O, Forras-Kaufman Z, Kaufman E, Fruehauf H, Boesiger P, Fried M, Schwizer W, Fox MR. 2009. Effect of meal volume and calorie load on postprandial gastric function and emptying: studies under physiological conditions by combined fiber-optic pressure measurement and MRI. Am J Physiol Gastrointest Liver Physiol 297(5):G894-901.

Laurent C, Besancon P, Caporiccio B. 2007. Flavonoids from a grape seed extract interact with digestive secretions and intestinal cells as assessed in an in vitro digestion/Caco-2 cell culture model. Food Chem 100:1704-12.

Le Bourvellec C, Renard CMGC. 2011. Interactions between polyphenols and macromolecules: quantification methods and mechanisms. Crit Rev Food Sci Nutr 52:213-48.

Lebet V, Arrigoni E, Amado R. 1998. Digestion procedure using mammalian enzymes to obtain substrates for in vitro fermentation studies. Lebensmittel-Wissenschaft und -Technologie 31:509-15.

Lemmens L, Van Buggenhout S, Van Loey AM, Hendrickx ME. 2010. Particle size reduction leading to cell wall rupture is more important for the $\beta$-carotene bioaccessibility of raw compared to thermally processed carrots. J Agric Food Chem 58:12769-76.

Liang L, Wu X, Zhao T, Zhao J, Li F, Zou Y, Mao G, Yang L. 2012. In vitro bioaccessibility and antioxidant activity of anthocyanins from mulberry (Morus atropurpurea Roxb.) following simulated gastro-intestinal digestion. Food Res Intl 46:76-82.

Lin HC, Prather C, Fisher RS, Meyer JH, Summers RW, Pimentel M, McCallum RW, Akkermans LMA, Loening-Baucke V. 2005. Measurement of gastrointestinal transit. Dig Dis Sci 50:989-1004.

Lindahl A, Ungell AL, Knutson L, Lennernas H. 1997. Characterization of fluids from the stomach and proximal jejunum in men and women. Pharm Res 14:497-502.

Liu C-S, Glahn RP, Liu RH. 2004. Assessment of carotenoid bioavailability of whole foods using a Caco-2 cell culture model coupled with an in vitro digestion. J Agric Food Chem 52:4330-37.

Llorach R, Urpi-Sarda M, Jauregui O, Monagas M, Andres-Lacueva C. 2009. An LC-MS-based metabolomics approach for exploring urinary metabolome modifications after cocoa consumption. J Proteome Res 8:5060-8.

Lorrain B, Dangles O, Genot C, Dufour C. 2010. Chemical modeling of heme-induced lipid oxidation in gastric conditions and inhibition by dietary polyphenols. J Agric Food Chem 58:676-83.

Lorrain B, Dangles O, Loonis M, Armand M, Dufour C. 2012. Dietary iron-initiated lipid oxidation and its inhibition by polyphenols in gastric conditions. J Agric Food Chem 60:9074-81.

Ludwig IA, Paz de Peña M, Concepción C, Alan C. 2013. Catabolism of coffee chlorogenic acids by human colonic microbiota. Biofactors 39(6):623-32

Macfarlane GT, Macfarlane S, Gibson GR. 1998. Validation of a three-stage compound continuous culture system for investigating the effect of retention time on the ecology and metabolism of bacteria in the human colon. Microbial Ecol 35:180-7.

Macfarlane S, Woodmansey EJ, Macfarlane GT. 2005. Colonization of mucin by human intestinal bacteria and establishment of biofilm communities in a two-stage continuous culture system. Appl Environ Microbiol 71:7483-92.

Mahler GJ, Shuler ML, Glahn RP. 2009. Characterization of Caco-2 and HT29-MTX cocultures in an in vitro digestion/cell culture model used to predict iron bioavailability. J Nutr Biochem 20:494-502.

Manach C, Scalbert A, Morand C, Remesy C, Jimenez L. 2004.

Polyphenols: food sources and bioavailability. Am J Clin Nutr 79:727-47. 
Manach C, Williamson G, Morand C, Scalbert A, Rémésy C. 2005. Bioavailability and bioefficacy of polyphenols in humans. I. Review of 97 bioavailability studies. Am J Clin Nutr 81:230S-42S.

Mandalari G, Tomaino A, Rich GT, Lo Curto R, Arcoraci T, Martorana M, Bisignano C, Saija A, Parker ML, Waldron KW, Wickham MSJ. 2010. Polyphenol and nutrient release from skin of almonds during simulated human digestion. Food Chem 122:1083-8.

Manzano S, Williamson G. 2010. Polyphenols and phenolic acids from strawberry and apple decrease glucose uptake and transport by human intestinal Caco-2 cells. Mol Nutr Food Res 54:1773-80.

Marciani L, Gowland PA, Spiller RC, Manoj P, Moore RJ, Young P, Fillery-Travis AJ. 2001. Effect of meal viscosity and nutrients on satiety, intragastric dilution, and emptying assessed by MRI. Am J Physiol Gastrointest Liver Physiol 280(6):G1227-33.

Marzorati M, Abbeele P, Possemiers S, Benner J, Verstraete W, Wiele T. 2011. Studying the host-microbiota interaction in the human gastrointestinal tract: basic concepts and in vitro approaches. Ann Microbiol 61:709-15.

Mateo Anson N, van den Berg R, Havenaar R, Bast A, Haenen GRMM. 2009. Bioavailability of ferulic acid is determined by its bioaccessibility. J Cereal Sci 49:296-300.

Mateo Anson N, Aura AM, Selinheimo E, Mattila I, Poutanen K, van den Berg R, Havenaar R, Bast A, Haenen GR. 2011. Bioprocessing of wheat bran in whole wheat bread increases the bioavailability of phenolic acids in men and exerts antiinflammatory effects ex vivo. J Nutr 141:137-43.

Mathes SH, Wohlwend L, Uebersax L, von Mentlen R, Thoma DS, Jung RE, Gorlach C, Graf-Hausner U. 2010. A bioreactor test system to mimic the biological and mechanical environment of oral soft tissues and to evaluate substitutes for connective tissue grafts. Biotechnol Bioengr 107: 1029-39.

McClements DJ, Li Y. 2010. Review of in vitro digestion models for rapid screening of emulsion-based systems. Food Funct 1:32-59.

McClements DJ, Decker EA, Park Y. 2008. Controlling lipid bioavailability through physicochemical and structural approaches. Crit Rev Food Sci Nutr 49:48-67.

McCoy MG, Sun GS, Marchadier D, Maugeais C, Glick JM, Rader DJ. 2002. Characterization of the lipolytic activity of endothelial lipase. J Lipid Res 43:921-9.

McDougall GJ, Fyffe S, Dobson P, Stewart D. 2005a. Anthocyanins from red wine- their stability under simulated gastrointestinal digestion. Phytochemistry 66:2540-8.

McDougall GJ, Dobson P, Smith P, Blake A, Stewart D. 2005b. Assessing potential bioavallability of raspberry anthocyanins using an in vitro digestion system. J Agric Food Chem 53:5896-904.

McDougall GJ, Fyffe S, Dobson P, Stewart D. 2007. Anthocyanins from red cabbage - stability to simulated gastrointestinal digestion. Phytochemistry 68:1285-94.

McInerney JK, Seccafien CA, Stewart CM, Bird AR. 2007. Effects of high pressure processing on antioxidant activity, and total carotenoid content and availability, in vegetables. Innov Food Sci Emerg 8:543-48.

Miller DD, Schricker BR, Rasmussen RR, Van Campen D. 1981. An in vitro method for estimation of iron availability from meals. Am J Clin Nutr 34:2248-56.

Minekus M, Jelier M, Xiao J, Kondo S, Iwatsuki K, Kokubo S, Bos M, Dummewind B, Havenaar R. 2005. Effect of partially hydrolysed guar gum (PHGG) on the bioaccessibility of fat and cholesterol. Biosci Biotechnol Biochem 69(5):932-38.

Minekus M, Marteau P, Havenaar R, Huis in't Veldt JHJ. 1995. A multicompartmental dynamic computer-controlled model simulating the stomach and small intestine. Altern Lab Anim 2:197-209.

Minekus M, Smeets-Peeters M, Bernalier A, Marol-Bonnin S, Havennar R, Marteau P, Alric M, Fonty G, Huis in't Veld J. 1999. A computer controlled system to simulate conditions of the large intestine with peristaltic mixing, water absorption and absorption of fermentation products. Appl Microb Biotechn 53:108-14.

Mishellany-Dutour A, Peyron M-A, Croze J, François O, Hartmann C, Alric M, Woda A. 2011. Comparison of food boluses prepared in vivo and by the AM2 mastication simulator. Food Qual Prefer 22:326-31.

Mojaverian P. 1996. Evaluation of gastrointestinal pH and gastric residence time via the Heidelberg radiotelemetry capsule: pharmaceutical application. Drug Develop Res 38:73-85.

Mojaverian P, Vlasses PH, Kellner PE, Rocci JrML. 1988. Effects of gender, posture, and age on gastric residence time of an indigestible solid: pharmaceutical considerations. Pharm Res 5:639-44.
Molly K, Vande Woestyne M, Verstraete W. 1993. Development of a 5-step multi-chamber reactor as a simulation of the human intestinal microbial ecosystem. Appl Microbiol Biotechnol 39:254-8.

Mortensen PB, Clausen MR. 1996. Short-chain fatty acids in the human colon: relation to gastrointestinal health and disease. Scand J Gastroenterol Suppl 216:132-48.

Nater UM, Bohus M, Abbruzzese E, Ditzen B, Gaab J, Kleindienst N, Ebner-Priemer U, Mauchnik J, Ehlert U. 2010. Increased psychological and attenuated cortisol and alpha-amylase responses to acute psychosocial stress in female patients with borderline personality disorder.

Psychoneuroendocrinology 35:1565-72.

Neilson AP, George JC, Janle EM, Mattes RD, Rudolph R, Matusheski NV, Ferruzzi MG. 2009. Influence of chocolate matrix composition on cocoa flavan-3-ol bioaccessibility in vitro and bioavailability in humans. J Agric Food Chem 57:9418-26.

Newton JL, James OF, Williams GV, Allen A. 2004. The diurnal profile of gastric pepsin activity is reduced with Helicobacter pylori infection. Dig Dis Sci 49:1103-8.

Nollevaux G, Deville C, El Moualij B, Zorzi W, Deloyer P, Schneider YJ, Peulen O, Dandrifosse G. 2006. Development of a serum-free co-culture of human intestinal epithelium cell-lines (Caco-2/HT29-5M21). BMC Cell Biol 7:20.

Öhrvik V, Witthöft C. 2008. Orange juice is a good folate source in respect to folate content and stability during storage and simulated digestion. Eur J Nutr 47(2):92-8.

Öhrvik VE, Büttner BE, Rychlik M, Lundin E, Witthöft CM. 2010. Folate bioavailability from breads and a meal assessed with a human stable-isotope area under the curve and ileostomy model. Am J Clin Nutr 92:532-8.

Oidtmann J, Schantz M, Mäder K, Baum M, Berg S, Betz M, Kulozik U, Leick S, Rehage H, Schwarz K, Richling E. 2012. Preparation and comparative release characteristics of three anthocyanin encapsulation systems. J Agric Food Chem 60:844-51

Ornelas-Paz JDJ, Failla ML, Yahia EM, Gardea-Bejar A. 2008. Impact of the stage of ripening and dietary fat on in vitro bioaccessibility of $\beta$-carotene in 'Ataulfo' mango. J Agric Food Chem 56:1511-6.

Ortega N, Reguant J, Romero MP, Macià A, Motilva MJ. 2009. Effect of fat content on the digestibility and bioaccessibility of cocoa polyphenol by an in vitro digestion model. J Agric Food Chem 57:5743-9.

Ortega N, Macià A, Romero MP, Reguant J, Motilva MJ. 2011. Matrix composition effect on the digestibility of carob flour phenols by an in vitro digestion model. Food Chem 124:65-71.

Palafox-Carlos H, Ayala-Zavala JF, González-Aguilar GA. 2011. The role of dietary fiber in the bioaccessibility and bioavailability of fruit and vegetable antioxidants. J Food Sci 76:R6-15.

Parada J, Aguilera JM. 2007. Food microstructure affects the bioavailability of several nutrients. J Food Sci 72:R21-32.

Patton JS, Carey MC. 1981. Inhibition of human pancreatic lipase-colipase activity by mixed bile salt-phospholipid micelles. Am J Physiol 241:G328-36.

Pearson JP, Roberts NB. 2001. Mucosal protective effects of ecabet sodium: pepsin inhibition and interaction with mucus. Clin Sci (Lond) 100:411-7.

Perez de la Cruz Moreno M, Oth M, Deferme S, Lammert F, Tack J, Dressman J, Augustijns P. 2006. Characterization of fasted-state human intestinal fluids collected from duodenum and jejunum. J Pharm Pharmacol 58:1079-89.

Perez-Vicente A, Gil-Izquierdo A, Garcia-Viguera C. 2002. In vitro gastrointestinal digestion study of pomegranate juice phenolic compounds, anthocyanins, and vitamin C. J Agric Food Chem 50:2308-12.

Pimpão RC, Dew T, Figueira ME, McDougall GJ, Stewart D, Ferreira RB, Santos CN, Williamson G. 2014. Urinary metabolite profiling identifies novel colonic metabolites and conjugates of phenolics in healthy volunteers. Mol Nutr Food Res. DOI: 10.1002/mnfr.201300822.

Poquet L, Clifford MN, Williamson G. 2008. Transport and metabolism of ferulic acid through the colonic epithelium. Drug Metab Dispos 36(1):190-7.

Porrini M, Riso P, Testolin G. 1998. Absorption of lycopene from single or daily portions of raw and processed tomato. Br J Nutr 80: 353-61.

Possemiers S, Rabot S, Espin JC, Bruneau A, Philippe C, González-Sarrías A, Heyerick A, Tomás-Barberán FA, De Keukeleire D, Verstraete W. 2008. Eubacterium limosum activates isoxanthohumol from hops (Humulus lupulus L.) into the potent phytoestrogen 8-prenylnaringenin in vitro and in rat intestine. J Nutr 138:1310-6. 
Possemiers S, Bolca S, Eeckhaut E, Depypere H, Verstraete W. 2007. Metabolism of isoflavones, lignans and prenylflavonoids by intestinal bacteria: producer phenotyping and relation with intestinal community. FEMS Microbiol Ecol 61:372-83.

Possemiers S, Bolca S, Verstraete W, Heyerick A. 2011. The intestinal microbiome: a separate organ inside the body with the metabolic potential to influence the bioactivity of botanicals. Fitoterapia 82:53-66.

Poulaert M, Borel P, Caporiccio B, Gunata Z, Dhuique-Mayer C. 2012. Grapefruit juices impair the bioaccessibility of $\beta$-carotene from orange-fleshed sweet potato but not its intestinal uptake by Caco-2 cells. J Agric Food Chem 60:685-91.

Reboul E, Richelle M, Perrot E, Desmoulins-Malezet C, Pirisi V, Borel P. 2006. Bioaccessibility of carotenoids and vitamin $\mathrm{E}$ from their main dietary sources. J Agric Food Chem 54:8749-55.

Rechner AR, Smith MA, Kuhnle G, Gibson GR, Debnam ES, Srai SKS, Moore KP, Rice-Evans CA. 2004. Colonic metabolism of dietary polyphenols: influence of structure on microbial fermentation products. Free Radic Biol Med 36:212-25.

Rios LY, Bennett RN, Lazarus SA, Remesy C, Scalbert A, Williamson G. 2002. Cocoa procyanidins are stable during gastric transit in humans. Am J Clin Nutr 76:1106-10

Rodriguez-Roque MJ, Rojas-Grau MA, Elez-Martinez P, Martin-Belloso O. 2013. Soymilk phenolic compounds, isoflavones and antioxidant activity as affected by in vitro gastrointestinal digestion. Food Chem 136:206-12.

Rohleder N, Nater UM. 2009. Determinants of salivary alpha-amylase in humans and methodological considerations. Psychoneuroendocrinology 34:469-85.

Rosa NN, Barron C, Gaiani C, Dufour C, Micard V. 2013a. Ultra-fine grinding increases the antioxidant capacity of wheat bran. J Cereal Sci 57:84-90.

Rosa NN, Dufour C, Lullien-Pellerin V, Micard V. 2013b. Physical and enzymatic destructuration of wheat aleurone layer improves its antioxidant capacity. Food Chem 141:2355-62.

Sambruy Y, Ferruzza S, Ranaldi G, De Angelis I. 2001. Intestinal cell culture models: applications in toxicology and pharmacology. Cell Biol Toxicol 17:301-17.

Sanchez-Patan F, Cueva C, Monagas M, Walton GE, Gibson GR, Quintanilla-Lopez JE, Lebron-Aguilar R, Martin-Alvarez PJ, Moreno-Arribas MV, Bartolome B. 2012. In vitro fermentation of a red wine extract by human gut microbiota: changes in microbial groups and formation of phenolic metabolites. J Agric Food Chem 60: 2136-47.

Sanz T, Luyten H. 2006. Release, partitioning and stability of isoflavones from enriched custards during mouth, stomach and intestine in vitro simulations. Food Hydrocoll 20:892-900.

Sawai Y, Kohsaka K, Nishiyama Y, Ando K. 1987. Serum concentrations of rutoside metabolites after oral administration of a rutoside formulation to humans. Arzneimittelforschung 37:729-32

Scalbert A, Morand C, Manach C, Remesy C. 2002. Absorption and metabolism of polyphenols in the gut and impact on health. Biomed Pharmacother 56:276-82.

Schantz M, Erk T, Richling E. 2010. Metabolism of green tea catechins by the human small intestine. Biotechnol J 5(10):1050-9.

Schramm DD, Karim M, Schrader HR, Holt RR, Kirkpatrick NJ, Polagruto JA, Ensunsa JL, Schmitz HH, Keen CL. 2003. Food effects on the absorption and pharmacokinetics of cocoa flavanols. Life Sci 73:85769.

Schulze K. 2006. Imaging and modelling of digestion in the stomach and the duodenum. Neurogastroenterol Motil 18:172-83.

Schweiggert RM, Mezger D, Schimpf F, Steingass CB, Carle R. 2012.

Influence of chromoplast morphology on carotenoid bioaccessibility of carrot, mango, papaya, and tomato. Food Chem 135:2736-42.

Selma M, Espín JC, Tomás Barberán FA. 2009. Interaction between phenolics and gut microbiota: role in human health. J Agric Food Chem 57:6485-501.

Sergent T, Dupont I, Jassogne C, Ribonnet L, van der Heiden E, Scippo ML, Muller M, McAlister D, Pussemier L, Larondelle Y, Schneider YJ. 2009. CYP1A1 induction and CYP3A4 inhibition by the fungicide imazali in the human intestinal Caco-2 cells-comparison with other conazole pesticides. Toxicol Lett 184:159-68.

Singleton VL, Rossi Jr JA. 1965. Colorimetry of total phenolics with phosphomolybdic-phosphotungstic acid reagents. Am J Enol Vitic 16:144-58.
Spencer JPE, Chaudry F, Pannala AS, Srai SK, Debnam E, Rice-Evans C. 2000. Decomposition of cocoa procyanidins in the gastric milieu. Biochem Biophys Res Commun 272:236-41.

Stahl W, van den Berg H, Arthur J, Bast A, Dainty J, Faulks RM, Gärtner C, Haenen G, Hollman P, Holst B, Kelly FJ, Cristina Polidori M, Rice-Evans C, Southon S, van Vliet T, Viña-Ribes J, Williamson G, Astley S. 2002. Bioavailability and metabolism. Mol Aspects Med 23:39-100.

Stalmach A, Mullen W, Barron D, Uchida K, Yokota T, Cavin C, Steiling H, Williamson G, Crozier A. 2009. Metabolite profiling of hydroxycinnamate derivatives in plasma and urine after the ingestion of coffee by humans: identification of biomarkers of coffee consumption. Drug Metab Dispos 37:1749-58

Sternby B, Hartmann D, Borgstrom B, Nilsson A. 2002. Degree of in vivo inhibition of human gastric and pancreatic lipases by Orlistat (tetrahydrolipstatin, THL) in the stomach and small intestine. Clin Nutr 21:395-402.

Suska A, Alehagen U, Lundström I, Dahlström U. 2012. Salivary $\alpha$-amylase activity, a new biomarker in heart failure? J Clin Exp Cardiolog S2:005.

Sy C, Gleize B, Dangles O, Landrier JF, Veyrat CC, Borel P. 2012a. Effects of physicochemical properties of carotenoids on their bioaccessibility, intestinal cell uptake, and blood and tissue concentrations. Mol Nutr Food Res 56:1385-97.

Sy C, Caris-Veyrat C, Dufour C, Boutaleb M, Borel P, Dangles O. 2012b. Inhibition by novel bacterial carotenoids of iron-induced peroxidation of linoleic acid in model gastric conditions. Comparison with common carotenoids. Food Funct 4:698-712.

Tabaqchali S, Hatzioannou J, Booth CC. 1968. Bile-salt deconjugation and steatorrhoea in patients with the stagnant-loop syndrome. Lancet 2: 12-6.

Tagliazucchi D, Verzelloni E, Bertolini D, Conte A. 2010. In vitro bio-accessibility and antioxidant activity of grape polyphenols. Food Chem 120:599-606.

Tagliazucchi D, Verzelloni E, Conte A. 2012. The first tract of alimentary canal as an extractor. Release of phytochemicals from solid food matrices during simulated digestion. J Food Biochem 36:555-68.

Tavares L, Figueira I, Macedo D, McDougall GJ, Leitão, MC, Vieira HLA, Stewart D, Alves PM, Ferreira RB, Santos CN. 2012. Neuroprotective effect of blackberry (Rubus sps) polyphenols is potentiated after simulated gastrointestinal digestion. Food Chem 131:1443-52.

Thakkar SK, Failla ML. 2008. Bioaccessibility of pro-vitamin A carotenoids is minimally affected by non pro-vitamin A xanthophylls in maize (Zea mays sp.). J Agric Food Chem 56:11441-6.

Thakkar SK, Maziya-Dixon B, Dixon AG, Failla ML. 2007. $\beta$-carotene micellarization during in vitro digestion and uptake by Caco- 2 cells is directly proportional to $\beta$-carotene content in different genotypes of cassava. J Nutr 137:2229-33.

Tulipani S, Llorach R, Jauregui O, Lopez-Uriarte P, Garcia-Aloy M, Bullo M, Salas-Salvado J, Andres-Lacueva C. 2011. Metabolomics unveils urinary changes in subjects with metabolic syndrome following 12-week nut consumption. J Proteome Res 10:5047-58.

Tyssandier V, Reboul E, Dumas J-F, Bouteloup-Demange C, Armand M, Marcand J, Sallas M, Borel P. 2003. Processing of vegetable-borne carotenoids in the human stomach and duodenum. Am J Physiol Gastrointest Liver Physiol 284:G913-23.

Ulleberg EK, Comi I, Holm H, Herud EB, Jacobsen M, Vegarud GE. 2011. Human gastrointestinal juices intended for use in in vitro digestion models. Food Dig 2:52-61

Vallejo F, Larrosa M, Escudero E, Zafrilla MP, Cerda B, Boza J, Garcia-Conesa MT, Espin JC, Tomas-Barberan FA. 2010. Concentration and solubility of flavanones in orange beverages affect their bioavailability in humans. J Agric Food Chem 58:6516-24.

Van Aken GA, Bomhof E, Zoet FD, Verbeek M, Oosterveld A. 2011. Differences in in vitro gastric behaviour between homogenized milk and emulsions stabilised by Tween 80 , whey protein, or whey protein and caseinate. Food Hydrocoll 25:781-8.

Van Deest BW, Fordtran JS, Morawski SG, Wilson JD. 1968. Bile salt and micellar fat concentration in proximal small bowel contents of ileectomy patients. J Clin Invest 47:1314-24.

Van den Abbeele P, Grootaert C, Marzorati M, Possemiers S, Verstraete W, Gerard P, Rabot S, Bruneau A, El Aidy S, Derrien M, Zoetendal E, Kleerebezem M, Smidt H, Van de Wiele T. 2010. Microbial community development in a dynamic gut model is reproducible, colon region specific, and selective for Bacteroidetes and Clostridium cluster IX. Appl Environ Microbiol 76:5237-46. 
Van den Abbeele P, Roos S, Eeckhaut V, MacKenzie DA, Derde M, Verstraete W, Marzorati M, Possemiers S, Vanhoecke B, Van Immerseel F, Van de Wiele T. 2012. Incorporating a mucosal environment in a dynamic gut model results in a more representative colonization by lactobacilli. Microb Biotechnol 5:106-15.

Van Dorsten FA, Peters S, Gross G, Gomez-Roldan V, Klinkenberg M, de Vos RC, Vaughan EE, van Duynhoven JP, Possemiers S, van de Wiele T, Jacobs DM. 2012. Gut microbial metabolism of polyphenols from black tea and red wine/grape juice is source-specific and colon-region dependent. J Agric Food Chem 60:11331-42.

Van Het Hof KH, West CE, Weststrate JA, Hautvast JGAJ. 2000. Dietary factors that affect the bioavailability of carotenoids. J Nutr 130:503-6.

Vardakou M, Mercuri A, Barker S, Craig DM, Faulks R, Wickham MJ. 2011. Achieving antral grinding forces in biorelevant in vitro models: comparing the USP dissolution apparatus II and the dynamic gastric model with human in vivo data. AAPS J 12:620-6.

Veda S, Kamath A, Platel K, Begum K, Srinivasan K. 2006. Determination of bioaccessibility of $\beta$-carotene in vegetables by in vitro methods. Mol Nutr Food Res 50:1047-52.

Walsh KR, Zhang YC, Vodovotz Y, Schwartz SJ, Failla ML. 2003. Stability and bioaccessibility of isoflavones from soy bread during in vitro digestion. J Agric Food Chem 51:4603-9.

Walsh KR, Haak SJ, Bohn T, Tian Q, Schwartz SJ, Failla ML. 2007.

Isoflavonoid glucosides are deconjugated and absorbed in the small intestine of human subjects with ileostomies. Am J Clin Nutr 85 1050-6.

Wang P, Liu HJ, Mei XY, Nakajima M, Yin LJ. 2012. Preliminary study into the factors modulating $\beta$-carotene micelle formation in dispersions using an in vitro digestion model. Food Hydrocoll 26:427-33.
Wisen O, Johansson C. 1992. Gastrointestinal function in obesity-motility, secretion, and absorption following a liquid test meal. Metabolism 41: $390-5$.

Woda A, Mishellany-Dutour A, Batier L, François O, Meunier JP, Reynaud B, Alric M, Peyron MA. 2010. Development and validation of a mastication simulator. J Biomech 43:1667-73.

Worsoe J, Fynne L, Gregersen T, Schlageter V, Christensen L, Dahlerup J, Rijkhoff N, Laurberg S, Krogh K. 2011. Gastric transit and small intestinal transit time and motility assessed by a magnet tracking system. BMC Gastroenterol 11:145.

Wright AJ, Pietrangelo C, MacNaughton A. 2008. Influence of simulated upper intestinal parameters on the efficiency of beta carotene micellarisation using an in vitro model of digestion. Food Chem 107:1253-60.

Wroblewski K, Muhandiram R, Chakrabartty A, Bennick A. 2001. The molecular interaction of human salivary histatins with polyphenolic compounds. Eur J Biochem 268:4384-97.

Yonekura L, Nagao A. 2009. Soluble fibers inhibit carotenoid micellization in vitro and uptake by Caco-2 cells. Biosci Biotechnol Biochem 73: 196-9.

Yu LX, Crison JR, Amidon GL. 1996. Compartmental transit and dispersion model analysis of small intestinal transit flow in humans. Intl J Pharm 140:111-8

Zangenberg NH, Mullertz A, Kristensen HG, Hovgaard L. 2001a. A dynamic in vitro lipolysis model. I. Controlling the rate of lipolysis by continuous addition of calcium. Eur J Pharm Sci 14:115-22.

Zangenberg NH, Mullertz A, Kristensen HG, Hovgaard L. 2001b. A dynamic in vitro lipolysis model. II: evaluation of the model. Eur J Pharm Sci 14:237-44. 